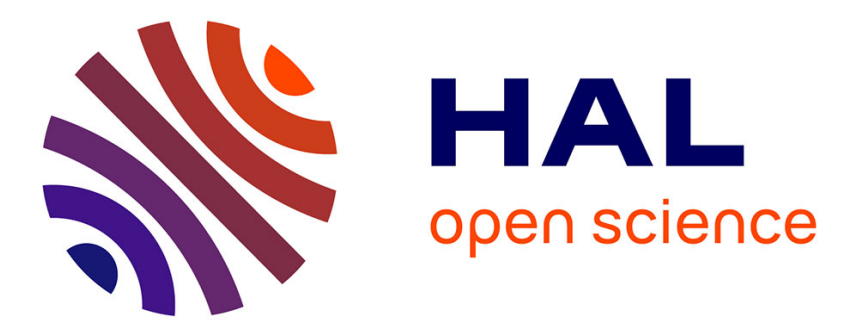

\title{
Green Fab Lab Applications of large-area waste polymer-based additive manufacturing
}

Dennis J Byard, Aubrey L Woern, Robert B Oakley, Matthew J Fiedler, Samantha L Snabes, Joshua Pearce

\section{To cite this version:}

Dennis J Byard, Aubrey L Woern, Robert B Oakley, Matthew J Fiedler, Samantha L Snabes, et al.. Green Fab Lab Applications of large-area waste polymer-based additive manufacturing. Additive Manufacturing, 2019, 27, pp.515-525. 10.1016/j.addma.2019.03.006 . hal-02111342

\section{HAL Id: hal-02111342 \\ https://hal.science/hal-02111342}

Submitted on 26 Apr 2019

HAL is a multi-disciplinary open access archive for the deposit and dissemination of scientific research documents, whether they are published or not. The documents may come from teaching and research institutions in France or abroad, or from public or private research centers.
L'archive ouverte pluridisciplinaire HAL, est destinée au dépôt et à la diffusion de documents scientifiques de niveau recherche, publiés ou non, émanant des établissements d'enseignement et de recherche français ou étrangers, des laboratoires publics ou privés. 
Preprint: Dennis J. Byard, Aubrey L. Woern, Robert B. Oakley, Matthew J. Fiedler, Samantha L. Snabes, and Joshua M. Pearce. Green Fab Lab Applications of Large-Area Waste Polymer-based Additive Manufacturing. Additive Manufacturing (2019, in press).

https://doi.org/10.1016/j.addma.2019.03.006

\title{
Green Fab Lab Applications of Large-Area Waste Polymer-based Additive Manufacturing
}

Dennis J. Byard ${ }^{1}$, Aubrey L. Woern ${ }^{1}$, Robert B. Oakley ${ }^{2}$, Matthew J. Fiedler ${ }^{2}$, Samantha L. Snabes ${ }^{2}$, and Joshua M. Pearce ${ }^{3,4,5^{*}}$

1 Department of Mechanical Engineering-Engineering Mechanics, Michigan Technological University, Houghton, MI

2 re:3D Inc, 1100 Hercules STE 220, Houston ,TX

3 Department of Material Science \& Engineering, Michigan Technological University, Houghton, MI

4 Department of Electrical \& Computer Engineering, Michigan Technological University, Houghton, MI

5 Department of Electronics and Nanoengineering, School of Electrical Engineering, Aalto University, Espoo, Finland

* Correspondence: pearce@mtu.edu; Tel.: +01-906-487-1466

\begin{abstract}
Fab labs, which offer small-scale distributed digital fabrication, are forming a Green Fab Lab Network, which embraces concepts of an open source symbiotic economy and circular economy patterns. With the use of industrial 3D printers capable of fused particle fabrication/ fused granular fabrication (FPF/FGF) printing directly from waste plastic streams, green fab labs could act as defacto recycling centers for converting waste plastics into valuable products for their communities. Clear financial drivers for this process have not been studied in the past. Thus, in this study the Gigabot X, an open source industrial 3D printer, which has been shown to be amenable to a wide array of recyclables for FPF/FGF 3D printing, is used to evaluate this economic potential. An economic life cycle analysis of the technology is completed comprised of three cases studies using FPF for large sporting equipment products. Sensitivities are run on the electricity costs for operation, materials costs from various feed stocks and the capacity factors of the 3D printers. The results showed that FPF/FGF 3D printing is capable of energy efficient production of a wide range of large high-value sporting goods products. In all cases, a substantial economic savings was observed when comparing the materials and energy related costs to commercial goods (even for customized goods). Using locally-sourced shredded plastic represented not only the best environmental option, but also the most economic. For the case study products analyzed even the lowest capacity factor (starting only one print per week) represented a profit when comparing to high-end value products. For some products the profit potential and return on investment was substantial (e.g. over 1000\%) for high capacity use of a Gigabot X. The results clearly show that open source industrial FPF/FGF 3D printers have significant economic potential when used as a distributed recycling/manufacturing system using recyclable feed stocks in the green fab lab context.
\end{abstract}

Keywords: polymers; recycling; waste plastic; upcycle; circular economy 
Preprint: Dennis J. Byard, Aubrey L. Woern, Robert B. Oakley, Matthew J. Fiedler, Samantha L. Snabes, and Joshua M. Pearce. Green Fab Lab Applications of Large-Area Waste Polymer-based Additive Manufacturing. Additive Manufacturing (2019, in press).

https://doi.org/10.1016/j.addma.2019.03.006

\section{Introduction}

A fab lab (or fabrication lab) is a small-scale workshop, which offers personal digital fabrication [1,2]. The lab itself functions as a technology prototyping platform for individuals to make their ideas a reality [3]. Fab labs are set up to foster learning, curiosity, creativity, experimentation, innovation, and invention [4]. These actions are encouraged through both hands-on making and open knowledge sharing [3,4]. Each fab lab provides a common set of tools, which include digital fabrication tools like laser cutters, CNC mills, and 3D printers. Fab labs train users to fabricate with these tools and provides access to make products for themselves. There are now more than 1,000 fab labs across the globe [5,6]. By empowering people to fabricate their ideas while being supported both locally (in the fab lab) and globally (the fab lab network and larger open source community), fab labs offer the potential for open source appropriate technology to flourish $[7,8]$, particularly when coupled to additive manufacturing to drive sustainable development [9].

A Green Fab Lab Network is forming, which is a globally distributed design team [10]. The Green Fab Lab Network utilizes the concepts of open source symbiotic economies [11,12], biomimicry [13-15], regenerative design [16-19], and circular economy patterns [20-22]. For example, Fab Lab Barcelona has a Green Fab Lab project that aims to explore how digital fabrication can support a more sustainable lifestyle $[23,24]$. This is possible because digital distributed manufacturing with 3D printers has been shown to be less environmentally detrimental than conventional manufacturing [25-27] because of improved materials efficiency and reduced embodied energy of transportation [28,29]. Although the ecological benefits of distributed manufacturing with AM can be substantial, these can be improved further with the use of the most ecologically friendly materials. For example, distributed plastic recycling can be used to provide materials from local waste. This involves upcycling post-consumer polymer waste into 3D printing filament [30] with a recyclebot, which is an open source waste plastic extruder [31]. Environmental life cycle analysis (LCA) performed on the recyclebot production of filament showed the embodied energy of 3D printing filament could be reduced by $90 \%$ compared to manufacturing traditional filament [32-34]. By enabling true distributed recycling nearly all energy use from transportation as well as the pollution from transportation are eliminated, which tightens the loop of the circular economy making it more efficient [35]. Several types of recyclebot devices have been developed. This includes open source recyclebot variations from Filastruder, Lyman Plastic Bank, Perpetual Plastic and Precious Plastic. In addition, Felfil (OS), Filabot, Filastruder, Filafab, Filamaker (also has shredder), EWE, Extrusionbot, Noztek, and the Strooder provide fully commercialized versions of recyclebot technology [36]. In addition, following the RepRap (self replicating rapid prototyper) [37-39] method of making parts for a 3D printer using the machine, a "RepRapable Recyclebot" has been developed [40], where the majority of the recyclebot's parts can themselves be 3D printed from waste plastic using RepRap-class 3D printers. Recyclebots have successfully recycled several thermoplastic filaments including poly lactic acid (PLA) [40-44], high density polyethylene (HDPE) [31,45,46], acrylonitrile butadiene styrene (ABS) [34,45,47], elastomers [48], and composites like both waste wood from furniture manufacturing [49] and carbon fiber reinforced polymers [50]).

Although this process is effective the mechanical properties of the polymer are degraded with each melt/extrude cycle $[41,42,51,52]$. Thus, each cycle including the recyclebot process during conventional fused filament fabrication (FFF) (also referred to as fused deposition modeling (FDM) on proprietary Stratasys printers) 3D printing the material is slightly down-cycled. Without the 
Preprint: Dennis J. Byard, Aubrey L. Woern, Robert B. Oakley, Matthew J. Fiedler, Samantha L. Snabes, and Joshua M. Pearce. Green Fab Lab Applications of Large-Area Waste Polymer-based Additive Manufacturing. Additive Manufacturing (2019, in press).

https://doi.org/10.1016/j.addma.2019.03.006

introduction of reinforcement (e.g. carbon fibers) or virgin polymer, this process of recycling is limited to about five cycles as the mechanical properties weaken to the point of eliminating many applications $[41,42]$. To minimize the count of melt and extrude cycles of recycled plastic used for FFF-based 3D printing, the actual fabrication of filament can be replaced with printing directly from a number of sources such as pellets of plastic, flakes of plastic, regrind or shreds of recycled plastic (or polymer "particles” here). Several types of 3D printers already using fused particle fabrication (FPF) (or sometimes referred to as fused granular fabrication (FGF)), which have been developed to accomplish this in university labs [53-58], the RepRap/maker community [59-61], hacking industrial robots [62] and commercial systems [63-67].

Fab labs normally have a number of desktop 3D printers, so their users are already familiar with the concepts of additive manufacturing. In addition, as these 3D printers generate a noticeable amount of waste from failed projects from novice designers there is an opportunity to recycle failed prints [30]. Moving to a higher-end industrial printer capable of printing directly from waste plastic streams is within their technical competency. This would enable fab labs to act to reach some of their promise of sustainability centers [68-70] by becoming defacto recycling centers for all kinds of waste plastics for their communities. To reach this promise, however there must be clear financial drivers to enable sustainable operation. Thus, in this study the Gigabot X, an open source industrial 3D printer, which has been shown to be amenable to a wide array of recyclable feed stocks for FPF/FGF 3D printing [71], is used to evaluate the economic potential for large-area FPF/FGF AM in the green fab lab context. Specifically an economic life cycle analysis of the technology is completed comprised of three cases studies using FPF for large sporting equipment products. Sensitivities are run on the electricity costs for operation, materials costs from various feed stocks and the capacity factors of the 3D printers. The results are analyzed and discussed.

\section{Materials and Methods}

\subsection{Recycled Materials}

Acrylonitrile butadiene styrene (ABS) and polypropylene (PP) was used for printing of the consumergrade products in this study. Overall pellet sizes successfully fed through the hopped ranged from a min of $0.006 \mathrm{~mm}^{2}$ to a max of $18.20 \mathrm{~mm}^{2}$ [71]. The recycled ABS was supplied by Northwest Polymers (Molalla, OR) and the PP tested was supplied by McDunnough, Inc. (Fenton, Michigan). Before printing $\mathrm{ABS}$ was dried in a vacuum oven at $70^{\circ} \mathrm{C}$ for 8 hours and no preparation was made for PP.

\subsection{AM Systems and Settings}

A prototype Gigabot X [71] shown in Figure 1 with the extruder detailed in the cutaway rendering shown in Figure 2 was used to print the materials. The extruder is a drop-in conversion for the standard Gigabot large format 3D printer [67]. It uses a scaled down version of an industrial extrusion screw to promote more consistent extrusion and mixing of materials [71]. The machine uses large nozzles (1.75 $\mathrm{mm}$ in diameter) allowing for rapid deposition of materials for reduced print times for large parts. All designs for the machine are open source allowing for customization modification by the user to adapt the printer to allow for new materials and use cases [67]. 3D models were sliced with Slic3r [72] and the printer was controlled with Marlin Firmware [73]. Optimal printing parameters were determined by the methodology outlined in [71]. As the system has two heating zones non-uniform particles are 
Preprint: Dennis J. Byard, Aubrey L. Woern, Robert B. Oakley, Matthew J. Fiedler, Samantha L. Snabes, and Joshua M. Pearce. Green Fab Lab Applications of Large-Area Waste Polymer-based Additive Manufacturing. Additive Manufacturing (2019, in press). https://doi.org/10.1016/j.addma.2019.03.006

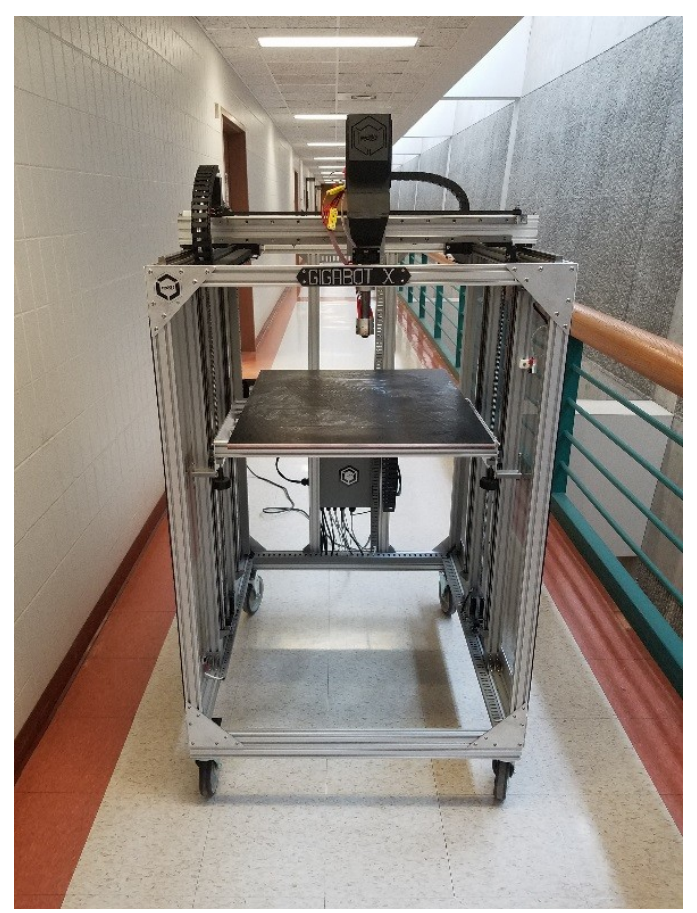

melted in zone 1 before they are 3D printed in zone 2, which enables the system to be robust through a wide range of sizes and materials [71].

Figure 1. Gigabot X.

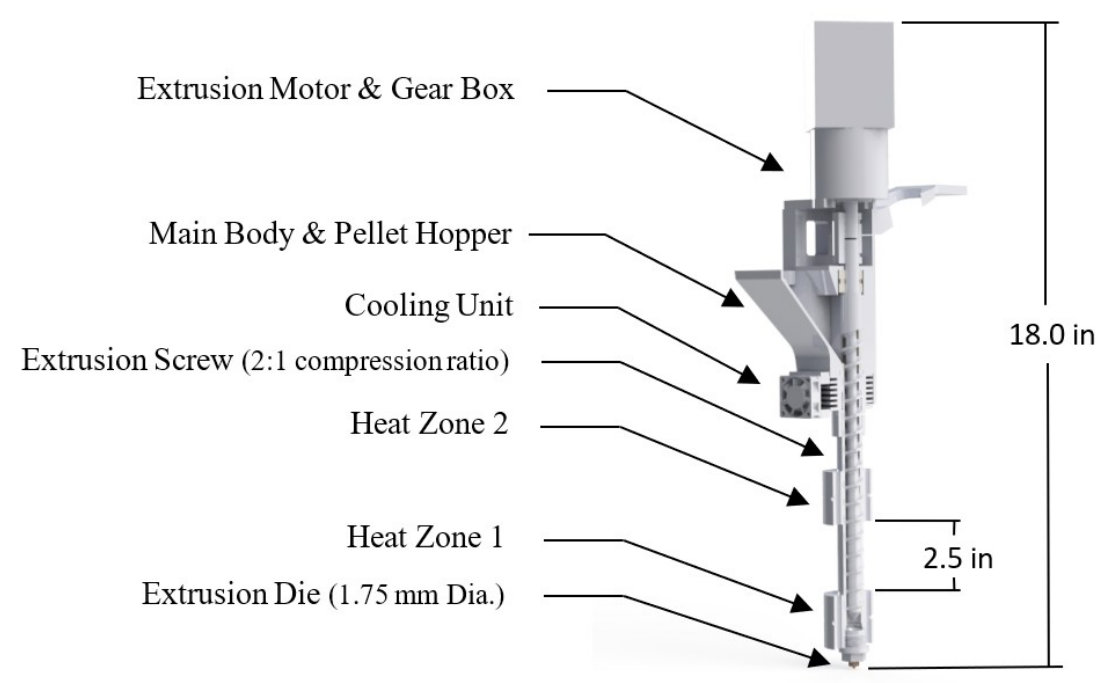

Figure 2. Gigabot X extruder with pellet/granules/particles and regrind feeder. 
Preprint: Dennis J. Byard, Aubrey L. Woern, Robert B. Oakley, Matthew J. Fiedler, Samantha L. Snabes, and Joshua M. Pearce. Green Fab Lab Applications of Large-Area Waste Polymer-based Additive Manufacturing. Additive Manufacturing (2019, in press).

https://doi.org/10.1016/j.addma.2019.03.006

The printer settings are shown in Table 1 for the case study components detailed in section 2.3. 
Preprint: Dennis J. Byard, Aubrey L. Woern, Robert B. Oakley, Matthew J. Fiedler, Samantha L. Snabes, and Joshua M. Pearce. Green Fab Lab Applications of Large-Area Waste Polymer-based Additive Manufacturing. Additive Manufacturing (2019, in press).

https://doi.org/10.1016/j.addma.2019.03.006

Table 1. 3D printer settings for all materials used in case studies.

\begin{tabular}{|c|c|c|c|c|c|c|}
\hline & Skateboard & Kayak Paddles & Snowshoe & Snowshoe Binding & Snowshoe Inserts & Snowshoe Straps \\
\hline Printer & Gigabot X & Gigabot X & Gigabot X & Gigabot X & Lulzbot & Lulzbot \\
\hline Material & ABS & ABS & ABS & $\mathrm{pp}$ & PLA & Ninjaflex \\
\hline Extrusion Width (mm) & 1.75 & 1.70 & 1.75 & 1.75 & 0.40 & 0.40 \\
\hline Heat Zone 1 Temp $\left({ }^{\circ} \mathrm{C}\right)$ & 240 & 240 & 240 & 235 & 210 & 220 \\
\hline Heat Zone 2 Temp $\left({ }^{\circ} \mathrm{C}\right)$ & 240 & 240 & 240 & 235 & N/A & N/A \\
\hline Bed Temp ( $\left.{ }^{\circ} \mathrm{C}\right)$ & 90 & 90 & 90 & 60 & 80 & 0 \\
\hline Print Speed (mm/s) & 35 & 20 & 35 & 35 & 50 & 15 \\
\hline Infill \% & 100 & 100 & 100 & 100 & 80 & 100 \\
\hline Z-Hop (mm) & 2 & 2 & 2 & 2 & 1 & 0 \\
\hline Layer Height (mm) & 1.000 & 1.000 & 1.000 & 1.000 & 0.200 & 0.375 \\
\hline Brim Loops & 10 & 15 & 10 & 0 & 0 & 0 \\
\hline Brim Layers & 3 & 2 & 3 & 0 & 0 & 0 \\
\hline
\end{tabular}

Another FFF 3D printer, the Lulzbot Taz, was used for the detailed parts as it has a $0.5 \mathrm{~mm}$ nozzle. It uses $2.85 \mathrm{~mm}$ filament and the parts were printed in polylactic acid (PLA) with 80\% infill or Ninjaflex at $0.2 \mathrm{~mm}$ layer height and at 100\% infill. Fab Labs already have access to such small desktop FFF 3D printers to make small detailed parts.

\subsection{Case studies}

Three sports mobility products were chosen as case studies from a large initial list of consumer grade products that could be printed by the Gigabot X. These products were selected based on their use of the build volume of the Gigabot X (e.g. they are not appropriate for standard desktop 3D printers because they are too large), a wide market and thus interest from makers using a fab lab as well as the general public, a variety of sizes (e.g. print times), a large and variable economic value and the ability to provide higher value by customization.

A skateboard, kayak paddles and snow shoes (Figures 3, 4 and 5, respectively) were selected as the case study products that would provide greater mobility in the summer, on water and in the winter. Case study products were designed utilizing open source software (Blender [81] and FreeCAD [82]) to ensure universal accessibility and customizability of products by the open source community.

Visual renderings of the portions of the products designated for FPF were prepared and used to provide initial estimates of time and material required to produce the final product. Additional hardware not suitable for FPF was then either sourced commercially or printed with more traditional FFF 3D 
Preprint: Dennis J. Byard, Aubrey L. Woern, Robert B. Oakley, Matthew J. Fiedler, Samantha L. Snabes, and Joshua M. Pearce. Green Fab Lab Applications of Large-Area Waste Polymer-based Additive Manufacturing. Additive Manufacturing (2019, in press). https://doi.org/10.1016/j.addma.2019.03.006

printing.

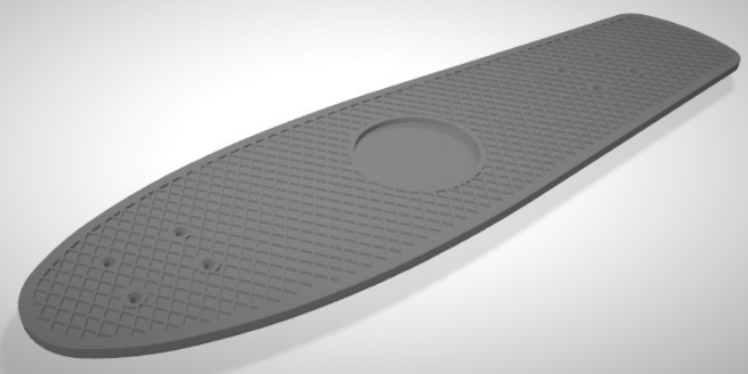

Figure 3. Skateboard CAD file prepared for print

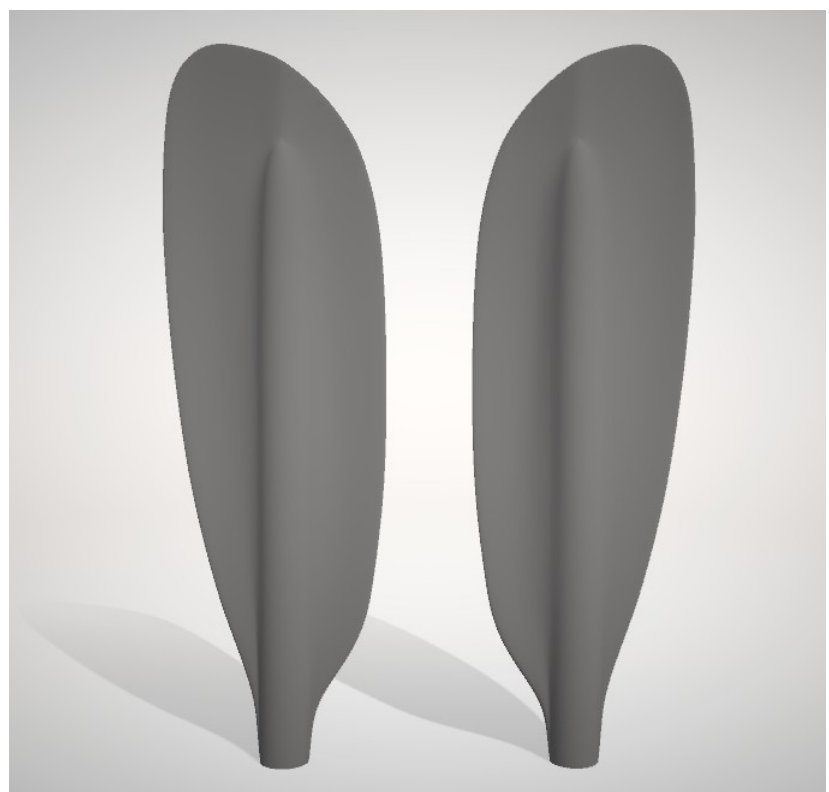

Figure 4. Kayak paddle CAD file prepared for print 
Preprint: Dennis J. Byard, Aubrey L. Woern, Robert B. Oakley, Matthew J. Fiedler, Samantha L. Snabes, and Joshua M. Pearce. Green Fab Lab Applications of Large-Area Waste Polymer-based Additive Manufacturing. Additive Manufacturing (2019, in press). https://doi.org/10.1016/j.addma.2019.03.006

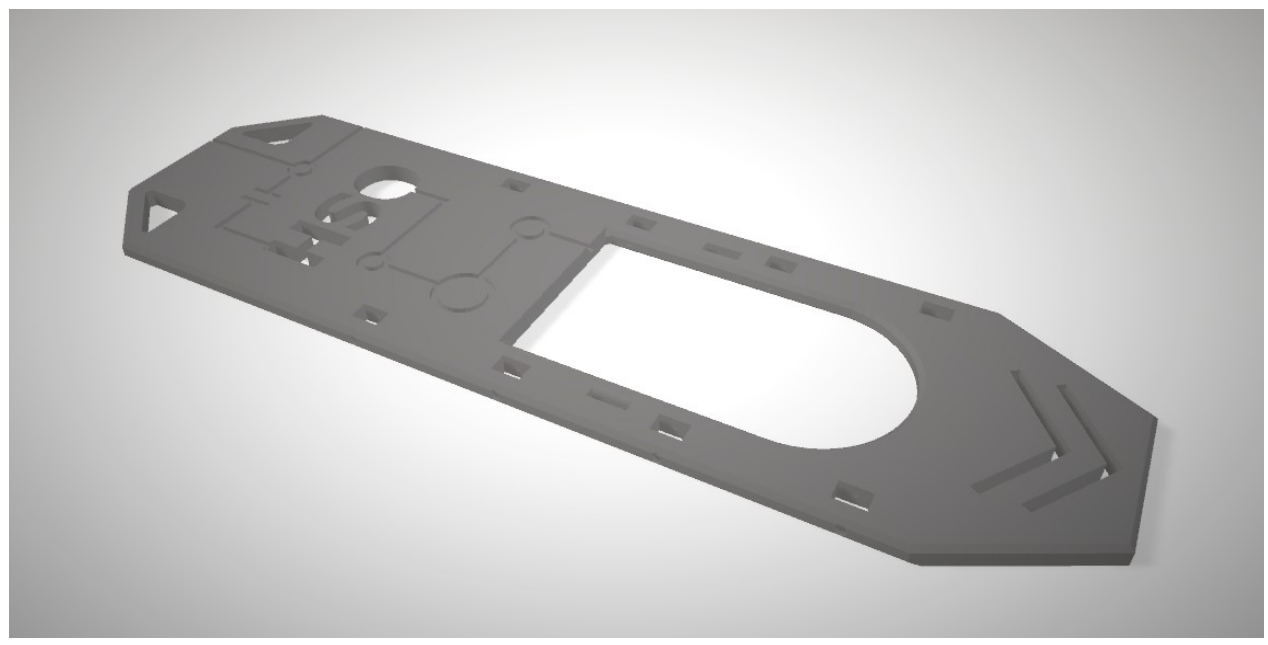

Figure 5. Snowshoe CAD file prepared for print

The skateboard shown in Figure 3 was designed in FreeCAD and printed as shown, using the Gigabot $\mathrm{X}$ system. The circular indentation located in the middle of the board was created to allow for the placement of high detail, multi-colored and fully customizable inserts, intended for print on an FFF system. The trucks and remaining hardware were sourced from commercially available options. They were not included in the economic analysis - only a direct comparison between commercial skateboard decks and the customizable 3D printable deck is used here.

Kayak paddles shown in Figure 4 were designed in Blender, with the intention of heat forming them onto an aluminum handle. Due to the use case of the kayak paddles, a smooth surface finish is required for optimal performance. This was to be achieved through sanding and an acetone painting process. Both child- and adult-sized versions of the kayak paddles were created, to better demonstrate the customizability of the process.

Note as shown in Figure 5, the snowshoes were printed entirely flat and a hot water bath was used post printing to bend up the front of the snow shoe. The part of the print needing reforming is placed in boiling water for 10 minutes and then bent between two pieces of wood. The process can be repeated until the required shape is met. The snowshoes were designed using FreeCAD and were meant to be assembled using a variety of smaller 3D printable components designated for FFF printing. A full assembly of components can be seen in Figure 6. 
Preprint: Dennis J. Byard, Aubrey L. Woern, Robert B. Oakley, Matthew J. Fiedler, Samantha L. Snabes, and Joshua M. Pearce. Green Fab Lab Applications of Large-Area Waste Polymer-based Additive Manufacturing. Additive Manufacturing (2019, in press).

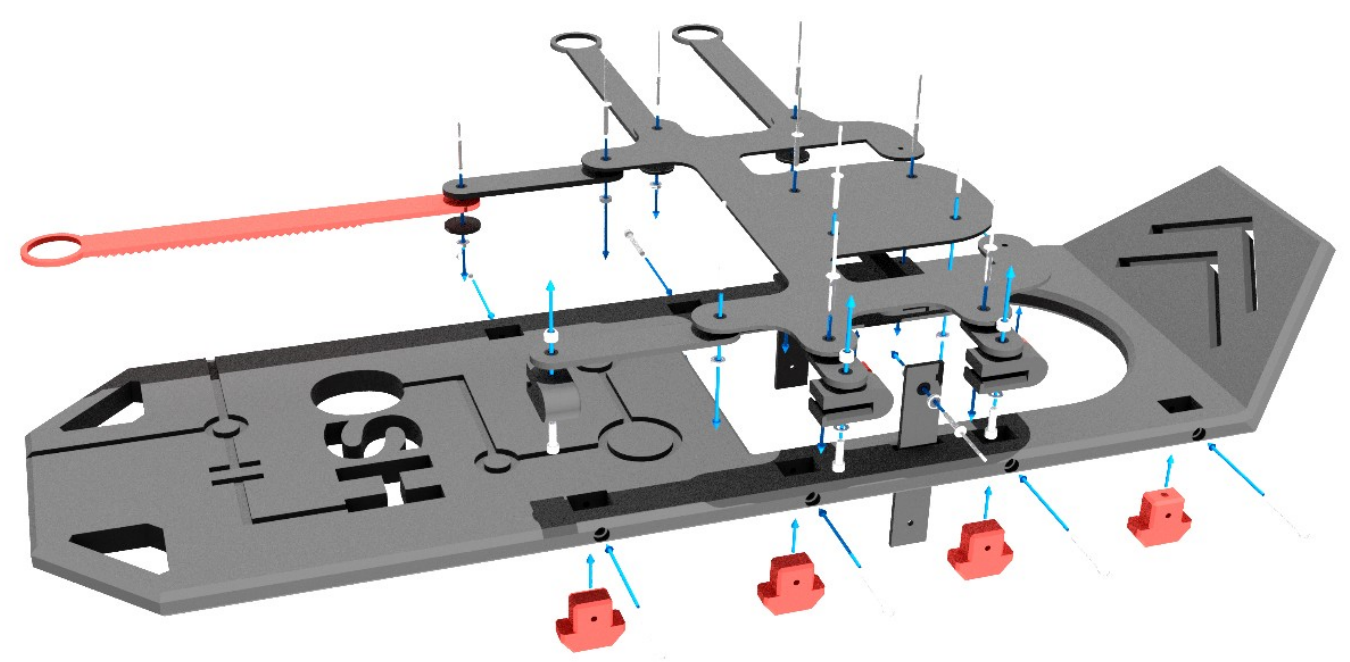

Figure 6. Snowshoe assembly exploded view

\subsection{Post Processing}

For post processing the large ABS parts, acetone smoothing was used to provide an improved surface finish. For parts like the Kayak paddle where surface finish would impact the functionality of the part, acetone was used to melt the layers together by chemically breaking down the outer surface of the plastic and blending together the peaks and valleys of each layer. A regular paintbrush was used to brush onto the part, and several applications were needed to get an adequate finish. An appropriate solvent should be used for each 3D printed plastic following [74]. This process should also be conducted in a well-ventilated area or fume hood.

\subsection{Economics}

\subsubsection{Capital Costs}

The Gigabot X (Fig. 1) will retail for 17,500.00 USD, the extruder shown in Fig. 2, will retail for 4,500 USD. Although some accountants may use a capital equipment depreciation of 3 to 5 years, the expected physical lifetime of the Gigabot is longer at 15 years, given the relatively high set aside for maintenance. Thus, 15 years will be used as the life cycle time for this study.

\subsubsection{Operational Costs}

The FPF 3D printer has an estimated maintenance costs of 500 USD/year assuming a capacity factor of $85 \%$ associated with replacement of small components such as heater cartridges, thermocouples, and cooling fans. The primary costs associated with operating the AM device are associated with the materials and electric costs. To obtain material costs as a function of time, multiple 
Preprint: Dennis J. Byard, Aubrey L. Woern, Robert B. Oakley, Matthew J. Fiedler, Samantha L. Snabes, and Joshua M. Pearce. Green Fab Lab Applications of Large-Area Waste Polymer-based Additive Manufacturing. Additive Manufacturing (2019, in press).

https://doi.org/10.1016/j.addma.2019.03.006

standard use case parts were run at optimum speed and flow rate slicer settings. Print times were recorded and parts were massed on a digital scale $( \pm 1 \mathrm{~g})$. Using this method, averaged material flow rate at optimized slicer settings was found to be $0.125 \mathrm{~kg} / \mathrm{hr}$. Electricity (electrical energy) use was monitored during extrusion printing with a multimeter $( \pm 0.005 \mathrm{~kW} \mathrm{~h})$ for each part during printing. Energy required for pre-heating the system was measured 10 times and averaged. Measurements were taken at room temperatures ranging from 23 to $24{ }^{\circ} \mathrm{C}$, bed temperatures between 60 and $90{ }^{\circ} \mathrm{C}$ and with temperature zones 1 and 2 ranging from 230 to $250{ }^{\circ} \mathrm{C}$. A sensitivity on the electricity costs ranged from $\$ 0.0953 / \mathrm{kWh}$ to $\$ 0.3203 / \mathrm{kWh}$ corresponding to low costs in Louisiana and high costs in Hawaii [75]. For comparison the U.S. average electricity cost is $\$ 0.1325 / \mathrm{kWh}$.

A range of materials costs were considered summarized in Table 2. Labor costs were not considered and will be discussed in detail below.

Table 2. Materials Costs

\begin{tabular}{|l|c|c|l|}
\hline Materials & Low cost (USD/Kg) & High cost (USD/Kg) & Sources \\
\hline $\begin{array}{l}\text { Filament (for comparison to } \\
\text { conventional FFF/FDM) }\end{array}$ & 15.00 & 35.00 & {$[76,77]$} \\
\hline Virgin Pellets & 2.84 & 9.34 & {$[78]$} \\
\hline Recycled Pellets & 1.10 & 2.20 & {$[79,80]$} \\
\hline Shredded Plastic $^{1}$ & 0.013 & 0.044 & {$[35]$} \\
\hline
\end{tabular}

1. Shredded plastic costs assumed the shredding was occurring in the fab lab for zero labor costs using free waste materials. The only cost was thus the cost for electricity to run a shredder similar to [35], which found the energy consumption for shredding $1 \mathrm{~kg}$ of ABS is $0.138 \mathrm{kWh}$ and shredding rate is $4.358 \mathrm{~kg} / \mathrm{h}$. The low and high costs are calculated from the low and high electricity costs of 0.0953 and $0.3203(\$ / \mathrm{kWh})$ [75], respectively. This is the case where the recyclables were already relatively clean- e.g. PP vials and bottles or ABS toys - collected for the purpose of recycling. If the waste stream was single source mixed then cleaning and sorting would need to be added to the costs.

For the capacity factor a number of scenarios are evaluated including 1) continuous printing (e.g. after each print a new one is started regardless of time of day or night), 2) one new print start per day, 2) two print starts per day (e.g. staring one at beginning of day and one at closing to print overnight), 3) maximum number of new print starts per 8 hour working day, and 4) one new print start weekly. The capacity factor will also thus depend on what object is being printed and over what length of time. To examine this three case studies are selected of products making use of the build volume of the Gigabot X.

\section{Calculations}

The cost calculations for distributed manufacturing followed [83]. The high and low commercial costs for each product were found using an Amazon search in July 2018 from conventional brick and mortar retailers, excluding shipping costs. The costs of the FPF-produced products $\left(C_{\mathrm{p}}\right)$ were calculated using energy and material consumption as measured and described above, and the pro-rated operation and maintenance cost of the Gigabot $\mathrm{X}$ as follows: 
Preprint: Dennis J. Byard, Aubrey L. Woern, Robert B. Oakley, Matthew J. Fiedler, Samantha L. Snabes, and Joshua M. Pearce. Green Fab Lab Applications of Large-Area Waste Polymer-based Additive Manufacturing. Additive Manufacturing (2019, in press). https://doi.org/10.1016/j.addma.2019.03.006

$$
C_{p}=E C_{e}+m C_{m}+\left(\frac{t}{T_{h}}\right) C_{o}\left(\frac{U S \$}{\text { product }}\right)
$$

where $E$ is energy use in $\mathrm{kW}$ h (this includes both pre-heating and printing electricity consumption), $C_{\mathrm{e}}$ is the electric rate in US\$/kWh used for a particular sensitivity run, $m$ is the polymer mass consumed in $\mathrm{kg}$ for a given product, and $C_{\mathrm{m}}$ is the cost of the materials in $\mathrm{US} \$ / \mathrm{kg}$, $\mathrm{t}$ is the time in hours to produce the printed product, $\mathrm{T}_{\mathrm{h}}$ is the lifetime of the Gigabot $\mathrm{X}$ in hours, and $\mathrm{C}_{\mathrm{o}}$ is the operation and maintenance cost of the Gigabot X over its lifetime in USD.

The number of new products $\left(\mathrm{P}_{\mathrm{y}}\right)$ of each case study type are calculated per year based on the four capacity factor scenarios to produce a total number of products $\left(T_{p}\right)$ in the Gigabot lifetime measured in years:

$$
T_{p}=T_{y} \times P_{y} \quad \text { (products) }
$$

The avoided costs $\left(C_{a}\right)$ for a product is the difference between the cost to manufacture with FPF $\left(\mathrm{C}_{\mathrm{p}}\right)$ and purchase conventionally. The total $\mathrm{a}=$ voided cost for each case study product is given by

$$
T_{a c}=T_{p} \times C_{a}=T_{p} \times\left(P_{c}-C_{p}\right)
$$

The percent change is given by:

$$
\frac{\left(P_{\text {Gigabot }}-P_{c}\right)}{P_{\text {Gigabot }}} \times 100 \%=\frac{C_{a}}{P_{\text {Gigabot }}} \times 100 \% \quad \text { (percent) }
$$

for the purchased retail costs $\left(\mathrm{P}_{\mathrm{c}}\right)$ for the low estimate $\left(P_{\mathrm{c}-\mathrm{low}}\right)$ and high estimate $\left(P_{\mathrm{c} \text {-high }}\right)$, respectively. The simple payback time $\left(t_{\mathrm{pb}}\right)$ of the Gigabot $\mathrm{X}$ is given by:

$t_{p b}=\frac{C_{\text {Gigabot }} \times t}{\sum C_{a}}=\frac{C_{\text {Gigabot }}}{\sum\left(P_{\text {Gigabot }}-P_{c}\right)}$

where $C_{\text {Gigabot }}$ is the cost of the Gigabot $\mathrm{X}$ and the sum is taken over a collection of products avoided for purchasing by 3D printing. The approximate return on investment $(R)$ for a RepRap in percent following [84] can be given by:

$t_{p b}=\frac{\left(1-e^{R T}\right)}{R}$

where $T$ is the lifetime of the Gigabot in years and assumed to be at least 15 years.

\section{Results}

The Gigabot X successfully produced three commercial grade sporting goods products from recycled waste as shown in Figures 7, 8, and 9 for skateboard, kayak paddles, and snow shoes, respectively. 
Preprint: Dennis J. Byard, Aubrey L. Woern, Robert B. Oakley, Matthew J. Fiedler, Samantha L. Snabes, and Joshua M. Pearce. Green Fab Lab Applications of Large-Area Waste Polymer-based Additive Manufacturing. Additive Manufacturing (2019, in press).

https://doi.org/10.1016/j.addma.2019.03.006

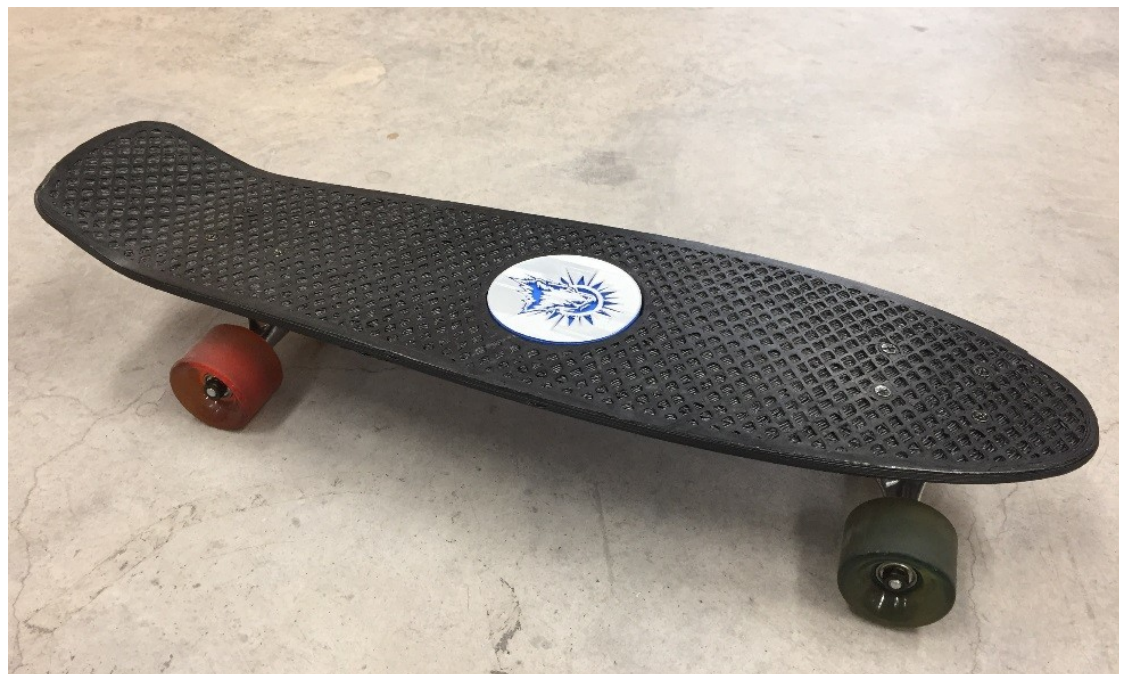

Figure 7. Finished skateboard

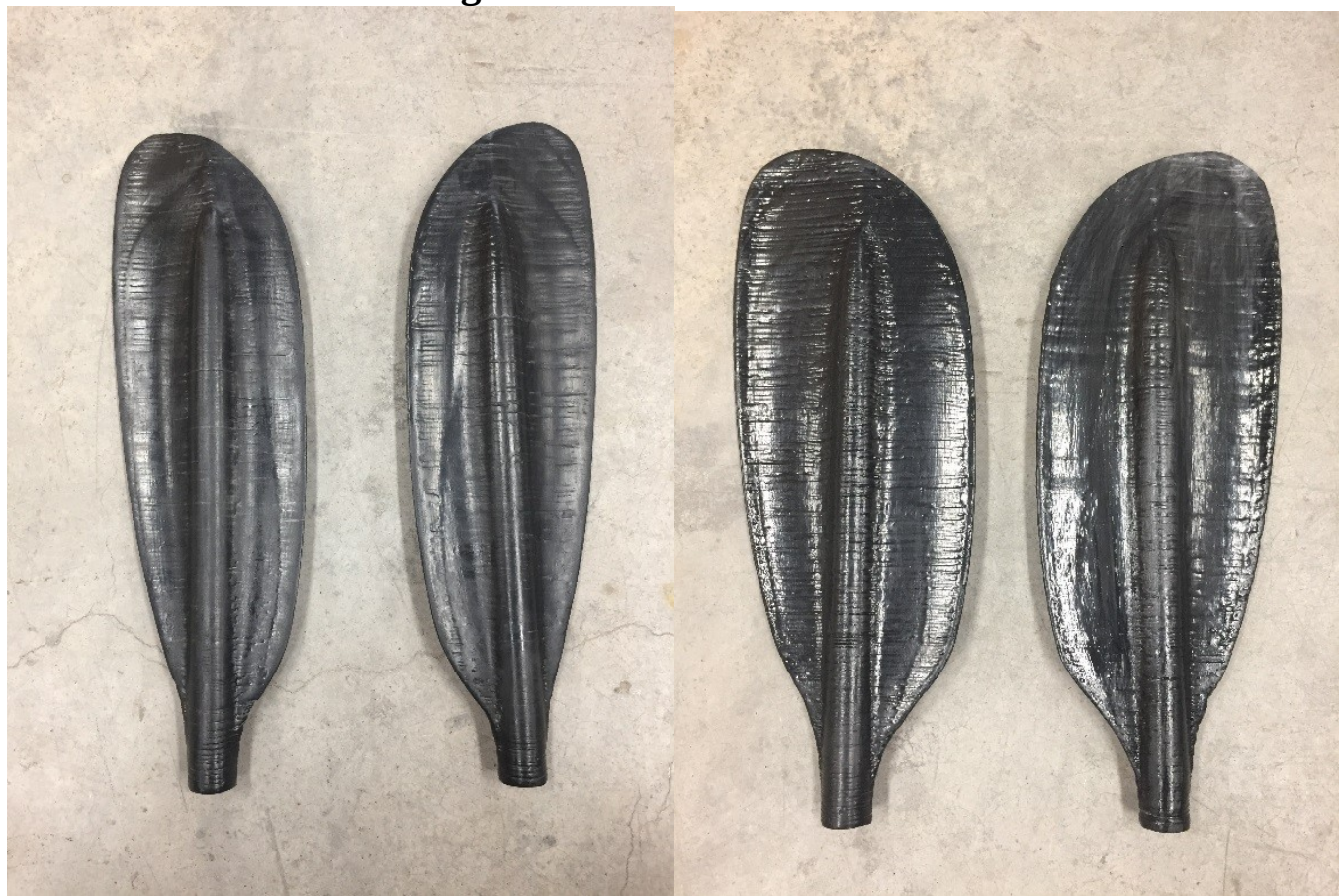

Figure 8 (a) Finished kayak paddles (children's version) and (b) Finished kayak paddles (Adult version) 
Preprint: Dennis J. Byard, Aubrey L. Woern, Robert B. Oakley, Matthew J. Fiedler, Samantha L. Snabes, and Joshua M. Pearce. Green Fab Lab Applications of Large-Area Waste Polymer-based Additive Manufacturing. Additive Manufacturing (2019, in press).

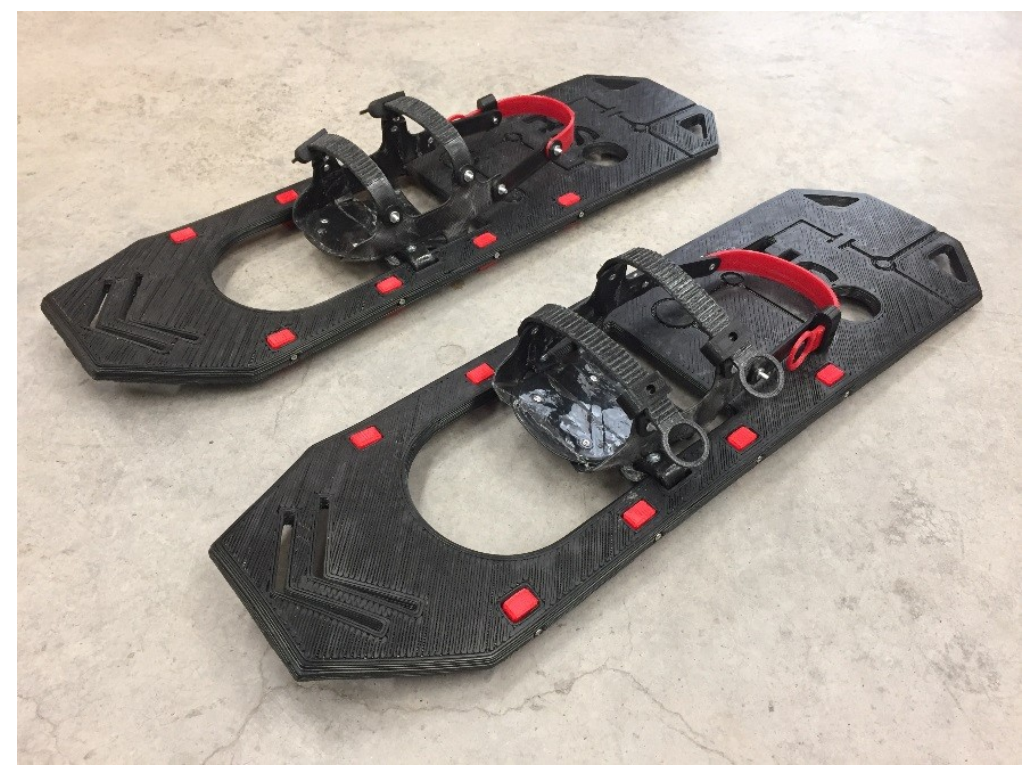

Figure 9. Finished snowshoes

The printing time for the case study products took 11 hours and 54 minutes for the skateboard, 3 hours 53 minutes (7 hours 45 minutes per set) for the kayak paddles, and 9 hours and 8 minutes (18 hours and 16 minutes per set) for the snow shows to print respectively. This corresponds to $0.127 \mathrm{~kg} / \mathrm{hr}, 0.067 \mathrm{~kg} /$ $\mathrm{hr}$ and $0.123 \mathrm{~kg} / \mathrm{hr}$ of printing speed for the various geometries (the paddles were printed vertically, which explains the roughly $1 / 2 x$ rate of deposition). The minimum energy required to preheat the system was found to be $0.23 \mathrm{kWh}$, the max was $0.36 \mathrm{kWh}$, with the averaged energy to preheat the system at $0.31 \mathrm{kWh}$. Once the Gigabot $\mathrm{X}$ is at temperature is uses $0.85 \mathrm{kwh} / \mathrm{hr}$ to operate. The cost to produce the products is shown in Figures 10, 11, and 12 as a function of the cost of electricity. 
Preprint: Dennis J. Byard, Aubrey L. Woern, Robert B. Oakley, Matthew J. Fiedler, Samantha L. Snabes, and Joshua M. Pearce. Green Fab Lab Applications of Large-Area Waste Polymer-based Additive Manufacturing. Additive Manufacturing (2019, in press). https://doi.org/10.1016/j.addma.2019.03.006

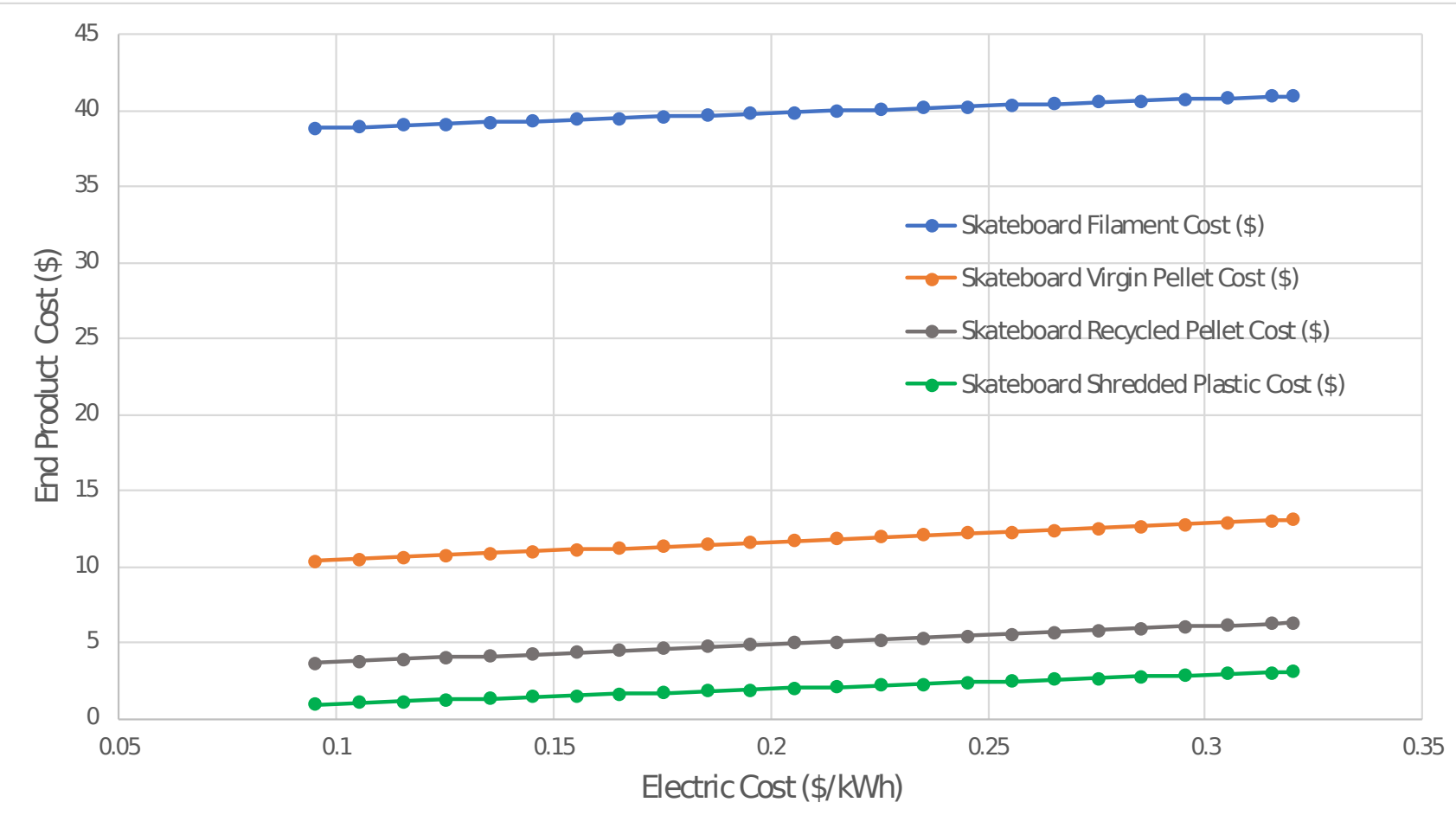

Figure 10. Economic cost to produce a skateboard as a function of the cost of electricity

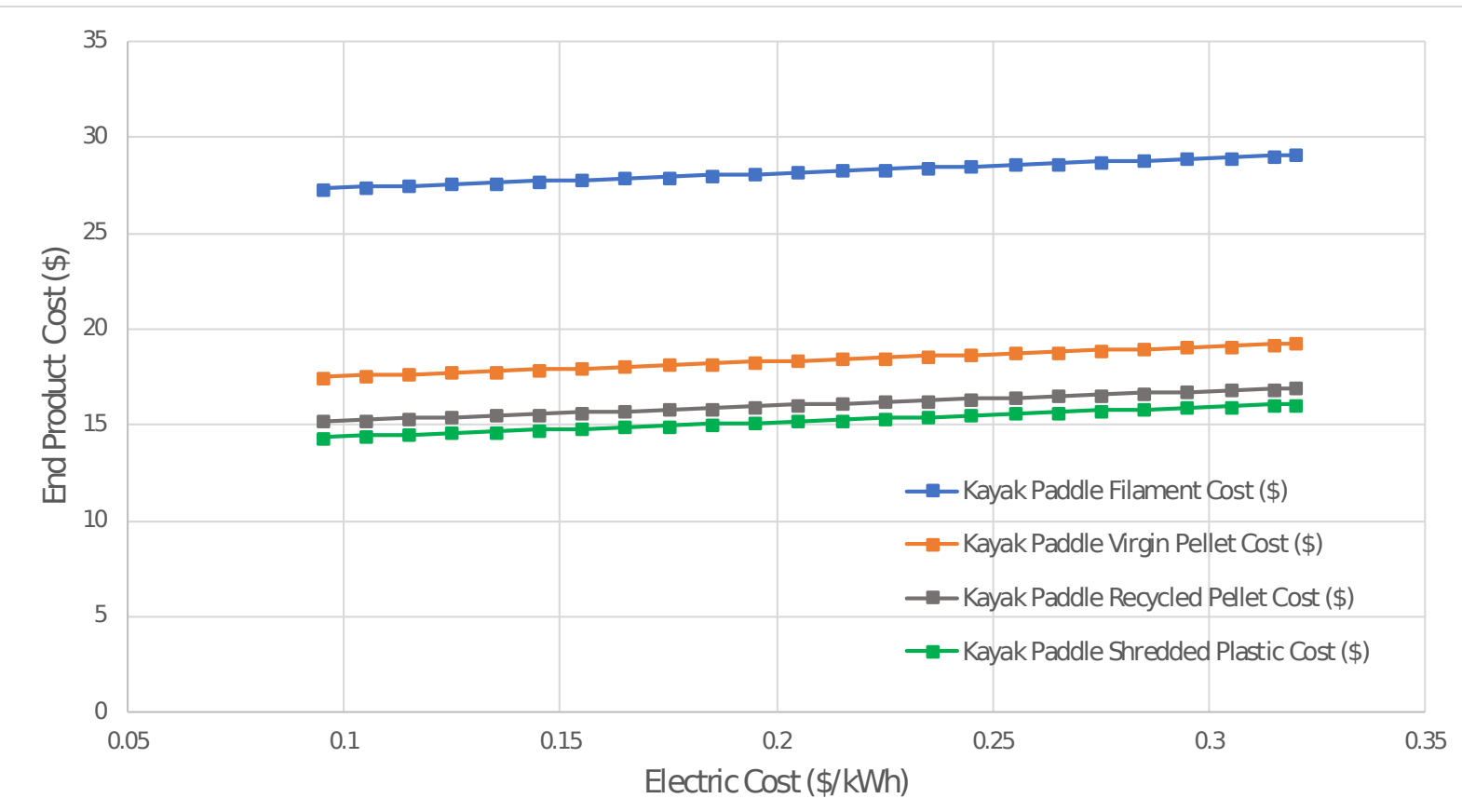

Figure 11. Economic cost to produce a kayak paddles as a function of the cost of electricity 
Preprint: Dennis J. Byard, Aubrey L. Woern, Robert B. Oakley, Matthew J. Fiedler, Samantha L. Snabes, and Joshua M. Pearce. Green Fab Lab Applications of Large-Area Waste Polymer-based Additive Manufacturing. Additive Manufacturing (2019, in press).

https://doi.org/10.1016/j.addma.2019.03.006

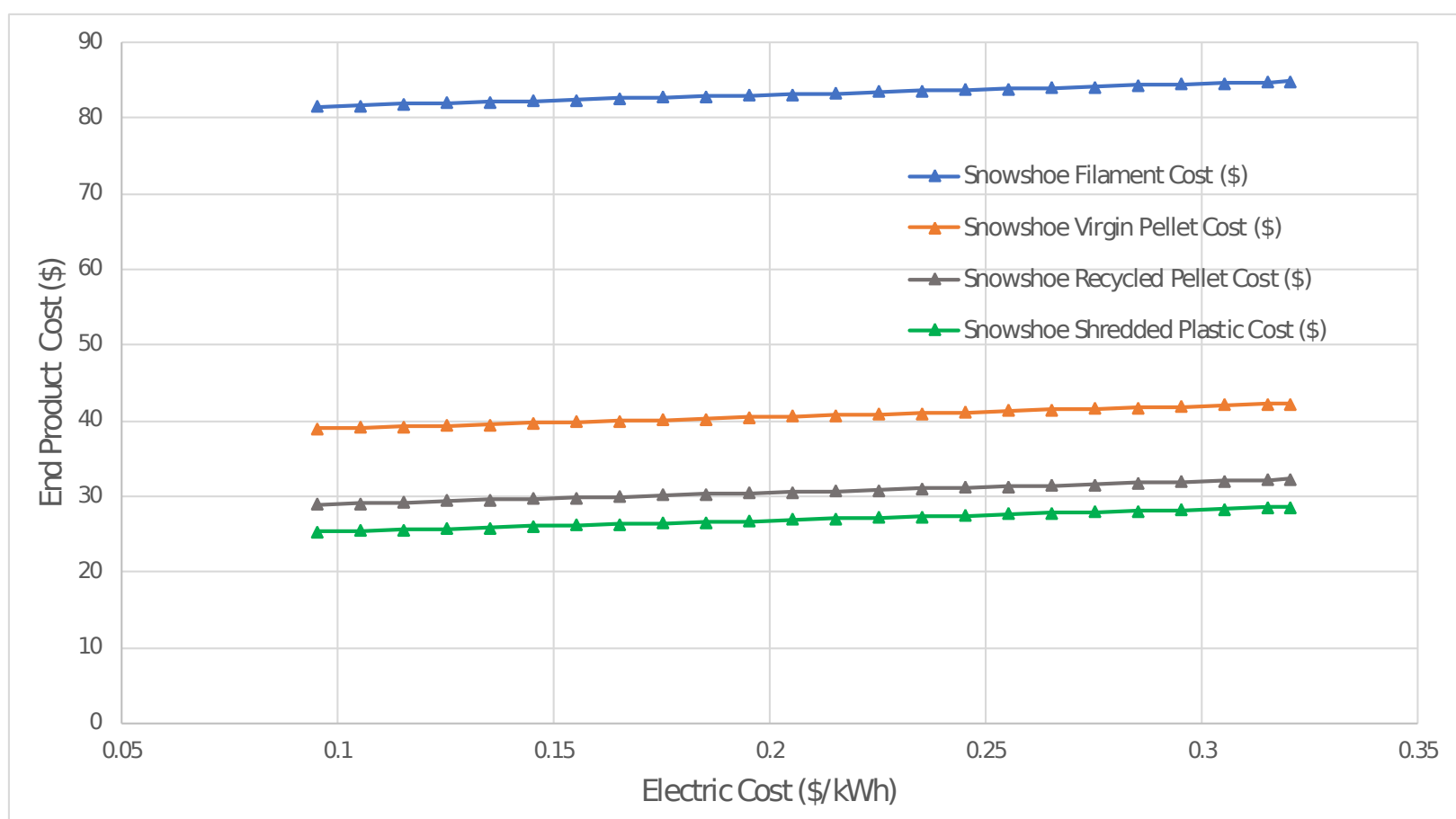

Figure 12. Economic cost to produce a snowshoe set as a function of the cost of electricity

First, it is clear that when looking at the costs of all three case study products the costs of using a Gigabot X to produce products from pellets or shredded plastic is significantly less than using filament regardless of the electricity costs found in the U.S. Despite the size of the Gigabot X, it uses $0.85 \mathrm{kWh} /$ $\mathrm{hr}$, which is less than operating a small microwave or hair dryer. This efficiency could be improved further in the future using several approaches such as a chemically appropriate bed to avoid heating, an insulated bottom to the heated bed, zone heating of the heated bed, an enclosure and more insulation on the hotend.

Comparing the Figures 10 through 12 it is clear that all products increase in cost as the price of electricity increases, however, in Figure 11, which displays cost data for the kayak paddles, the slightly steeper trend lines than compared to Figure 10 and 12 are due to the smaller (by weight) kayak paddles have a product cost that is more dependent on electric costs than larger products. In general, as material costs decrease, electric costs increase as a fraction of total product cost. This becomes increasingly important when using low-cost recycled plastics, where the material costs are brought close to zero. The magnitude of this effect can be seen in Table 3.

Table 3. Electric costs for operating the Gigabot X as a percent of total product cost at U.S. high and low values of electric prices. Note: It is assumed that the user pays out of pocket for the shredded plastic for which the only cost was the average cost of electricity to operate the shredder.

\begin{tabular}{lcccc} 
& Filament & Virgin Pellets & Recyded Pellets & Srredded Plastic \\
\hline Avg. \%日ec. Costs Low & $2.24 \%$ & $6.24 \%$ & $13.61 \%$ & $35.35 \%$ \\
Avg \%日ec. Costs High & $7.14 \%$ & $17.72 \%$ & $29.83 \%$ & $43.45 \%$
\end{tabular}


Preprint: Dennis J. Byard, Aubrey L. Woern, Robert B. Oakley, Matthew J. Fiedler, Samantha L. Snabes, and Joshua M. Pearce. Green Fab Lab Applications of Large-Area Waste Polymer-based Additive Manufacturing. Additive Manufacturing (2019, in press).

https://doi.org/10.1016/j.addma.2019.03.006

The costs of all the products can be compared in Figures 13 -15 assuming the average U.S. electric rate. These costs only include the material and electrical costs (e.g. marginal costs), whereas the machine costs are detailed in the next section.

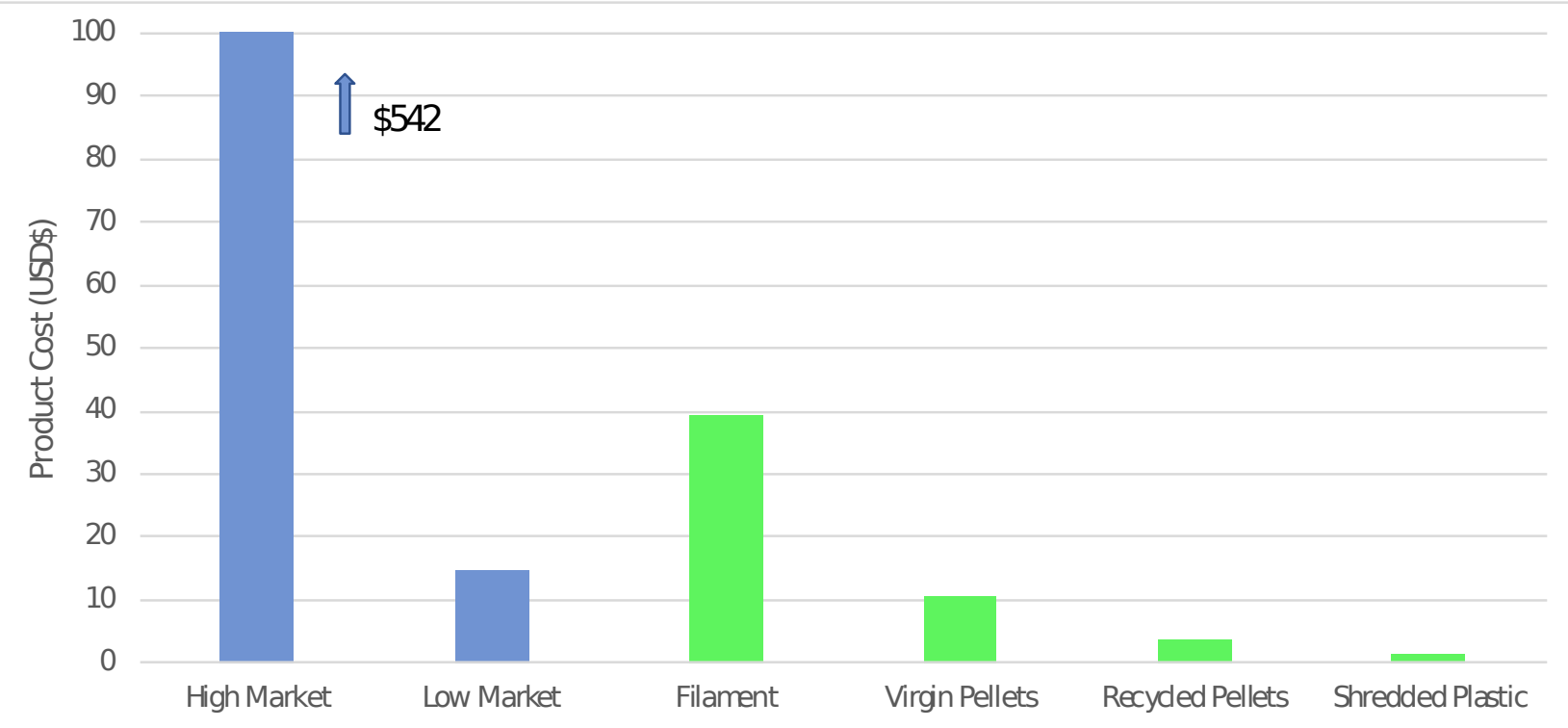

Figure 13. Skateboard, product cost by source.

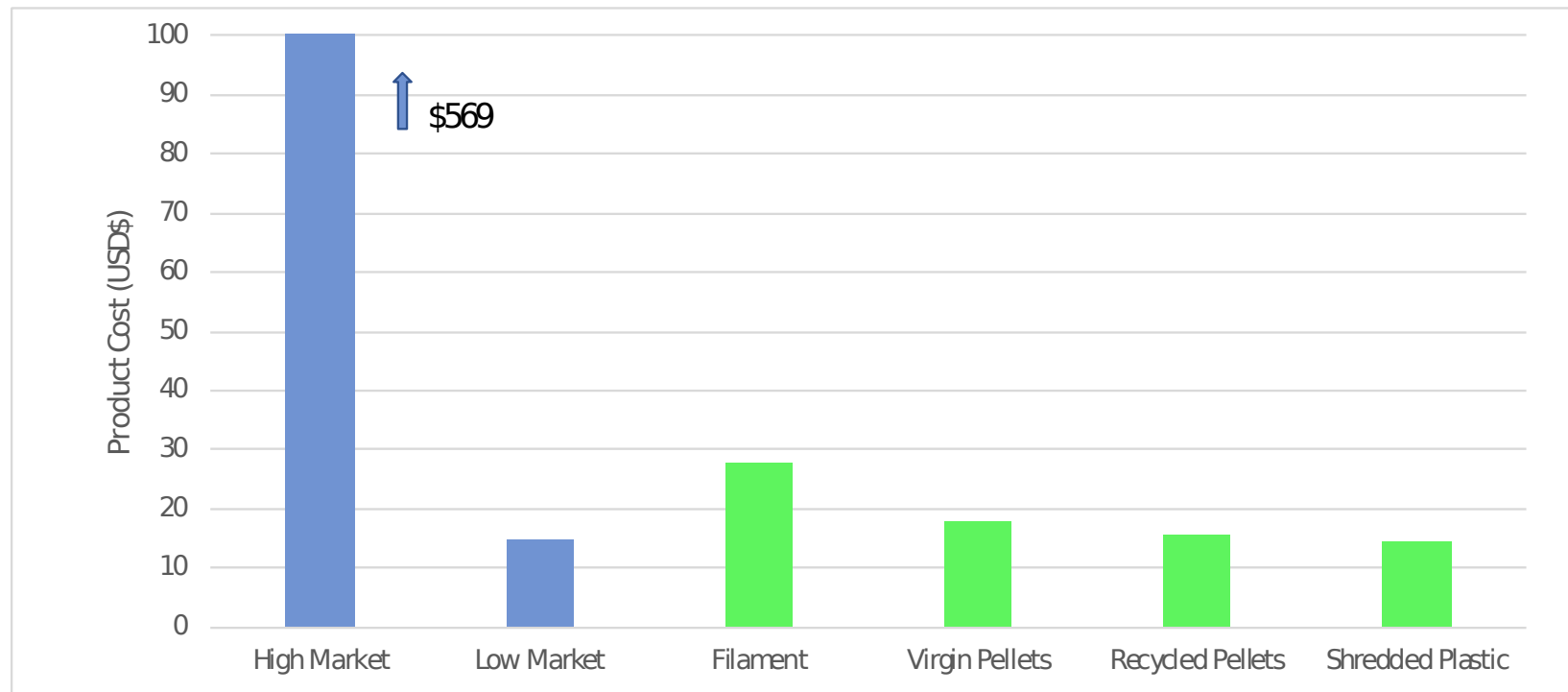

Figure 14. Kayak Paddle, product cost by source. 
Preprint: Dennis J. Byard, Aubrey L. Woern, Robert B. Oakley, Matthew J. Fiedler, Samantha L. Snabes, and Joshua M. Pearce. Green Fab Lab Applications of Large-Area Waste Polymer-based Additive Manufacturing. Additive Manufacturing (2019, in press). https://doi.org/10.1016/j.addma.2019.03.006

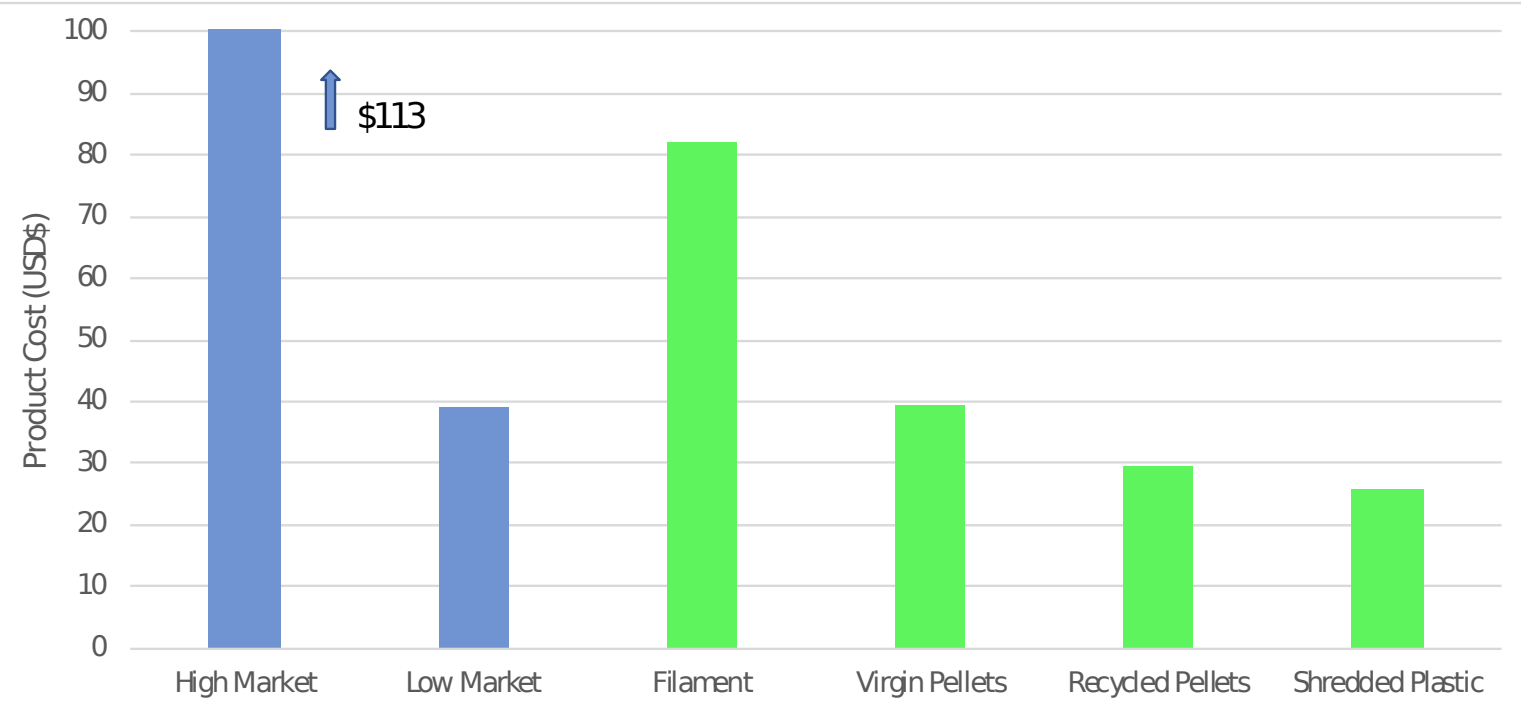

Figure 15. Snowshoe, product cost by source

The cost of the skateboard, kayak paddles, and snowshoes for commercial high and low prices, and distributed manufacturing with the Gigabot X with filament (purchased and cut up), virgin pellets, recycled pellets, and shredded plastic are shown in Figure 13-15. Please note the y-axis scale is limited to 100USD so the lower cost methods of manufacturing can be compared. As can be seen in Figures 13-15, any form of distributed manufacturing is significantly less costly than the high market price. The cost of filament is higher than the cost of the low market commercial products because of the high markup costs on commercial filament. In all cases, the use of shredded recycled plastic was less costly than the lowest commercial price product available on Amazon. Thus the marginal cost of producing any of the case study products is less than purchasing it.

To evaluate the economic potential of the greenest (least environmental impact scenario) a distributed recycling scenario [85-88] is assumed that fab lab users would grind their own waste plastic on site and then use it directly in the Gigabot X. Based on the four capacity factor scenarios the economics for the green fab lab using a single Gigabot $\mathrm{X}$ are summarized in Table 4 for a skateboard deck. The skateboard deck is the least complicated because there are no factors related to the purchased components (e.g. the costs of the aluminum poles needed for the kayak paddles would fluctuate significantly based on source location and tariffs and fees associated with current trading disputes). Market research shows the low and high costs for simple and highly customized skateboard decks are $\$ 14.80$ [89] and \$542 [90], respectively. The same data is shown for kayak paddles and snowshoes in Table 5 and 6, respectively. The low and high value savings found in column five, Table's 4-6, use the low and high cost comparisons found for the most similar objects on Amazon. 
Preprint: Dennis J. Byard, Aubrey L. Woern, Robert B. Oakley, Matthew J. Fiedler, Samantha L. Snabes, and Joshua M. Pearce. Green Fab Lab Applications of Large-Area Waste Polymer-based Additive Manufacturing. Additive Manufacturing (2019, in press).

https://doi.org/10.1016/j.addma.2019.03.006

Table 4. Skateboard 12 hr. print

\begin{tabular}{|c|c|c|c|c|c|c|c|c|}
\hline Scenario & $\begin{array}{c}\text { Capacity } \\
\text { Factor } \\
(\%) \\
\end{array}$ & $\begin{array}{l}\text { Prints } \\
\text { per } \\
\text { year }\end{array}$ & $\begin{array}{c}\text { Prints } \\
\text { over } \\
\text { lifetime }\end{array}$ & & $\begin{array}{l}\text { SD\$ saved/ } \\
\text { year } \\
\text { Low-high }\end{array}$ & $\begin{array}{l}\text { USD\$ saved/life- } \\
\text { time Low-high }\end{array}$ & $\begin{array}{c}\text { Payback } \\
\text { time } \\
\text { Low- } \\
\text { high } \\
\text { (years) }\end{array}$ & $\begin{array}{l}\text { ROI } \\
\text { Low- } \\
\text { high } \\
(\%)\end{array}$ \\
\hline \multirow[b]{2}{*}{ Continuous } & \multirow[b]{2}{*}{100.0} & \multirow[b]{2}{*}{730} & \multirow[b]{2}{*}{10950} & $\$$ & $9,263.70$ & \$ $138,955.50$ & 1.89 & 53 \\
\hline & & & & $\$$ & $394,119.70$ & $\$ 5,911,795.50$ & 0.04 & 2,273 \\
\hline \multirow[b]{2}{*}{$\begin{array}{l}\text { One new } \\
\text { start per day }\end{array}$} & \multirow[b]{2}{*}{50.0} & \multirow[b]{2}{*}{365} & \multirow[b]{2}{*}{5475} & $\$$ & $4,631.85$ & $\$ \quad 69,477.75$ & 3.78 & 26 \\
\hline & & & & $\$$ & $197,059.85$ & $\$ 2,955,897.75$ & 0.09 & 1,124 \\
\hline \multirow[b]{2}{*}{$\begin{array}{l}\text { Two starts } \\
\text { per day }\end{array}$} & \multirow[b]{2}{*}{100.0} & \multirow[b]{2}{*}{730} & \multirow[b]{2}{*}{10950} & $\$$ & $9,263.70$ & $\$ 138,955.50$ & 1.89 & 53 \\
\hline & & & & $\$$ & $394,119.70$ & $\$ 5,911,795.50$ & 0.04 & 2,273 \\
\hline \multirow[b]{2}{*}{$\begin{array}{l}\text { Max per one } \\
8 \text { hour shift }\end{array}$} & \multirow[b]{2}{*}{50.0} & \multirow[b]{2}{*}{365} & \multirow[b]{2}{*}{5475} & $\$$ & $4,631.85$ & $\$ \quad 69,477.75$ & 3.78 & 26 \\
\hline & & & & $\$$ & $197,059.85$ & $\$ 2,955,897.75$ & 0.09 & 1,124 \\
\hline \multirow[b]{2}{*}{$\begin{array}{l}\text { One new } \\
\text { print weekly }\end{array}$} & \multirow[b]{2}{*}{7.1} & \multirow[b]{2}{*}{52} & \multirow[b]{2}{*}{780} & $\$$ & 659.88 & $\$ \quad 9,898.20$ & -- & -- \\
\hline & & & & $\$$ & $28,074.28$ & $\$ 421,114.20$ & 0.62 & 161 \\
\hline
\end{tabular}

As can be seen in Table 4 all scenarios with the exception of making only a single print per week (using a capacity factor of $7.1 \%$ ) produced a profit. Some of these profits were quite substantial. So for example, a fab lab with a Gigabot X operating only as a skateboard deck manufacturer could expect to see a more than $\$ 2.9 \mathrm{~m}$ profit over the lifetime of the device even if operating only a single 8-hour shift for labor a day and selling at the high value or over $\$ 69,000$ at the low value. In reality, the market would likely be within these two extremes and a fab lab wishing to enter such a business would need to determine what salary they could afford to provide while still maintaining profitability. The worker, would of course only need to start and clear prints along with fix any major problems during a print. Thus, a worker could do other tasks (e.g. man the welcome desk at the fab lab, operate multiple Gigabots, etc.), which would make the marginal cost of operating a Gigabot X small.

The economics are similar for the case of a Gigabot X being used to only fabricate snowshoes. Based on the four capacity factor scenarios the economics for the green fab lab using a single Gigabot $\mathrm{X}$ with distributed recycled shredded waste are summarized in Table 5 for the snowshoes designed in this study. Market research shows the high and low costs for readily available commercial snow shoes are \$39 [92] and \$112.99 [91], respectively. Again, only the extreme case of producing only 1 per week was not economic. The ROI for all other capacity factors ranged from 10 to 240\% without including labor. For this case study there is some assembly required as shown in Figure 6, so if the snowshoes were either sold as kits or fully assembled the profit per snowshoe pair would be more towards the lower end value even with customizability benefits related to 3D printing are taken into account. 
Preprint: Dennis J. Byard, Aubrey L. Woern, Robert B. Oakley, Matthew J. Fiedler, Samantha L. Snabes, and Joshua M. Pearce. Green Fab Lab Applications of Large-Area Waste Polymer-based Additive Manufacturing. Additive Manufacturing (2019, in press).

https://doi.org/10.1016/j.addma.2019.03.006 
Preprint: Dennis J. Byard, Aubrey L. Woern, Robert B. Oakley, Matthew J. Fiedler, Samantha L. Snabes, and Joshua M. Pearce. Green Fab Lab Applications of Large-Area Waste Polymer-based Additive Manufacturing. Additive Manufacturing (2019, in press).

https://doi.org/10.1016/j.addma.2019.03.006

Table 5. Snowshoe 9 hour (18 hours for a set of two) print.

\begin{tabular}{|c|c|c|c|c|c|c|c|c|}
\hline Scenario & $\begin{array}{c}\text { Capacity } \\
\text { Factor } \\
(\%) \\
\end{array}$ & $\begin{array}{l}\text { Prints } \\
\text { per } \\
\text { year }\end{array}$ & $\begin{array}{c}\text { Prints } \\
\text { over life- } \\
\text { time } \\
\end{array}$ & & $\begin{array}{l}\text { D\$ saved/ } \\
\text { Low-high }\end{array}$ & $\begin{array}{c}\text { USD\$ saved/ } \\
\text { lifetime Low- } \\
\text { high }\end{array}$ & $\begin{array}{c}\text { Payback } \\
\text { time } \\
\text { Low- } \\
\text { high } \\
\text { (years) }\end{array}$ & $\begin{array}{c}\text { ROI } \\
\text { Low- } \\
\text { high (\%) }\end{array}$ \\
\hline \multirow[b]{2}{*}{ Continuous } & \multirow[b]{2}{*}{100.0} & \multirow[b]{2}{*}{486} & \multirow[b]{2}{*}{7300} & $\$$ & $5,918.84$ & $\$ \quad 88,782.60$ & 2.96 & 34 \\
\hline & & & & $\$$ & $41,927.31$ & $\$ 628,909.60$ & 0.42 & 240 \\
\hline \multirow{2}{*}{$\begin{array}{l}\text { One new } \\
\text { start per day }\end{array}$} & \multirow[b]{2}{*}{75.0} & \multirow[b]{2}{*}{365} & \multirow[b]{2}{*}{5475} & $\$$ & $4,439.13$ & $\$ \quad 66,586.95$ & 3.94 & 25 \\
\hline & & & & $\$$ & $31,445.48$ & $\$ 471,682.20$ & 0.56 & 180 \\
\hline \multirow{2}{*}{$\begin{array}{l}\text { Two starts } \\
\text { per day }\end{array}$} & \multirow[b]{2}{*}{100.0} & \multirow[b]{2}{*}{486} & \multirow[b]{2}{*}{7300} & $\$$ & $5,918.84$ & $\$ \quad 88,782.60$ & 2.96 & 34 \\
\hline & & & & $\$$ & $41,927.31$ & $\$ 628,909.60$ & 0.42 & 240 \\
\hline \multirow{2}{*}{$\begin{array}{l}\text { Max per one } \\
8 \text { hour shift }\end{array}$} & \multirow[b]{2}{*}{37.5} & \multirow[b]{2}{*}{182.5} & \multirow[b]{2}{*}{2737.5} & $\$$ & $2,219.57$ & $\$ \quad 33,293.48$ & 7.88 & 10 \\
\hline & & & & $\$$ & $15,722.74$ & $\$ 235,841.10$ & 1.11 & 90 \\
\hline \multirow{2}{*}{$\begin{array}{l}\text { One new } \\
\text { print weekly }\end{array}$} & \multirow[b]{2}{*}{10.7} & \multirow[b]{2}{*}{52} & \multirow[b]{2}{*}{780} & $\$$ & 632.42 & $9,486.36$ & -- & -- \\
\hline & & & & $\$$ & $4,479.90$ & $\$ \quad 67,198.56$ & 3.91 & 25 \\
\hline
\end{tabular}

The economics for producing kayak paddles is less clear as there is less of a direct comparison. First, there is not a comparable product as the wettability of the treated ABS provided an advantage over a standard kayak paddle as shown in Figure 10. This is an advantage for the 3D printed paddle because the need for a drip guard is eliminated as the paddle itself sheds water more easily. In addition, the commercial paddle is slightly more flexible indicating that to make an exact economic comparison more research is needed to choose an apples-to-apples comparison, potentially with composites of ABS and TPEs. On other performance metrics both paddles were comparable (e.g. ability to float if dropped, ease of use, and weight).

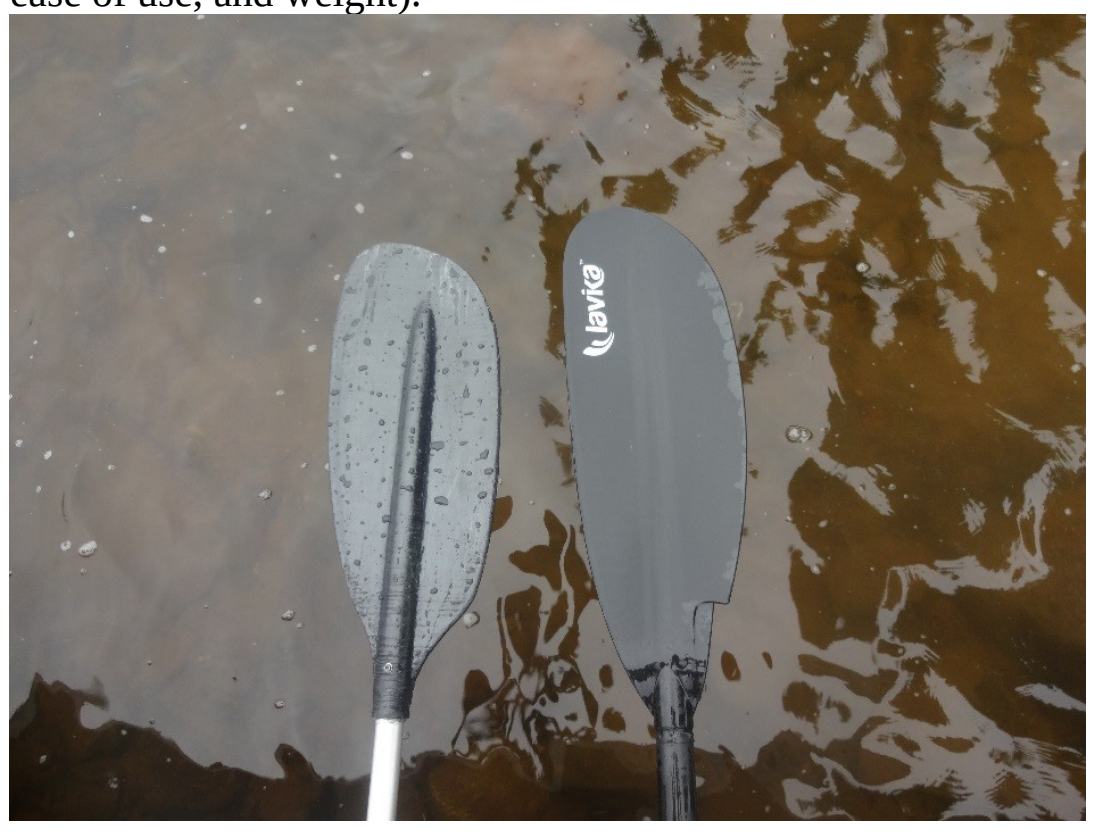


Preprint: Dennis J. Byard, Aubrey L. Woern, Robert B. Oakley, Matthew J. Fiedler, Samantha L. Snabes, and Joshua M. Pearce. Green Fab Lab Applications of Large-Area Waste Polymer-based Additive Manufacturing. Additive Manufacturing (2019, in press).

https://doi.org/10.1016/j.addma.2019.03.006

Figure 10. Comparing wetting of the 3D printed kayak paddle (left) and a commercial paddle (right).

Second, and perhaps more importantly, the cost of kayak paddles is dominated by the bar shown in an assembled kayak paddle in Figure 11. The aluminum pipe used for the cost comparison of the 3D printed kayak paddle was the worst-case scenario (e.g. single retail price at a local hardware store in the UP of Michigan). Market research shows the low and high cost for kayak paddles is \$14.99 [93] and $\$ 569$ [94], respectively. The cost of the aluminum pole alone was $\$ 13$, which left very little room for any additional costs to meet the lowest cost commercial paddle. Based on the four capacity factor scenarios the economics for the green fab lab using a single Gigabot $\mathrm{X}$ and locally shredded plastic are summarized in Table 6 for kayak paddles.

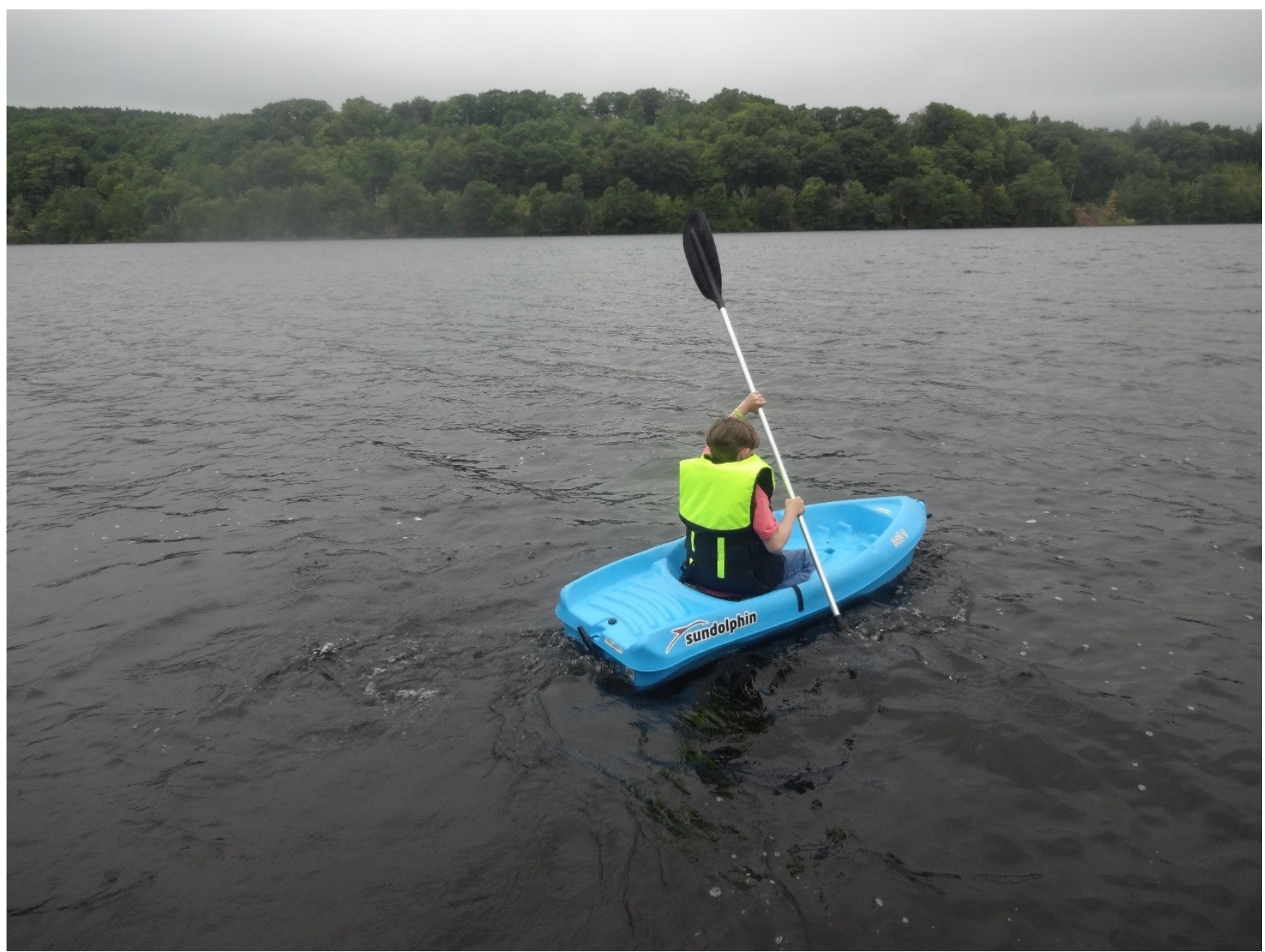

Figure 11. Assembled kayak paddle shown in use.

As can be seen in Table 6, none of the low-cost comparisons provide a payback or an ROI. The paybacks and ROIs were much better for the high cost scenarios, providing an ROI for example of $7 \%$ for even a single print per week which is what would be expected for long term investments on a balanced portfolio on the U.S. stock market. If operated optimally on 8 hour shifts this jumps to $77 \%$ 
Preprint: Dennis J. Byard, Aubrey L. Woern, Robert B. Oakley, Matthew J. Fiedler, Samantha L. Snabes, and Joshua M. Pearce. Green Fab Lab Applications of Large-Area Waste Polymer-based Additive Manufacturing. Additive Manufacturing (2019, in press).

https://doi.org/10.1016/j.addma.2019.03.006

ROI and over $230 \%$ if operated continually. 
Preprint: Dennis J. Byard, Aubrey L. Woern, Robert B. Oakley, Matthew J. Fiedler, Samantha L. Snabes, and Joshua M. Pearce. Green Fab Lab Applications of Large-Area Waste Polymer-based Additive Manufacturing. Additive Manufacturing (2019, in press).

https://doi.org/10.1016/j.addma.2019.03.006

Table 6. Paddles 4 hour (8 for set) print

\begin{tabular}{|c|c|c|c|c|c|c|c|c|}
\hline Scenario & $\begin{array}{c}\text { Capacity } \\
\text { Factor } \\
(\%) \\
\end{array}$ & $\begin{array}{c}\text { Prints } \\
\text { per } \\
\text { year }\end{array}$ & $\begin{array}{c}\text { Prints } \\
\text { over life- } \\
\text { time }\end{array}$ & & $\begin{array}{l}\text { SD\$ saved/ } \\
\text { ar Low-high }\end{array}$ & $\begin{array}{c}\text { USD\$ saved/ } \\
\text { lifetime Low- } \\
\text { high }\end{array}$ & $\begin{array}{c}\text { Payback } \\
\text { time } \\
\text { Low- } \\
\text { high } \\
\text { (years) }\end{array}$ & $\begin{array}{c}\text { ROI } \\
\text { Low- } \\
\text { high (\%) }\end{array}$ \\
\hline \multirow[b]{2}{*}{ Continuous } & \multirow[b]{2}{*}{100.0} & \multirow[b]{2}{*}{1095} & \multirow[b]{2}{*}{16425} & $\$$ & (208.05) & $\$ \quad(3,120.75)$ & -- & -- \\
\hline & & & & $\$$ & $606,432.90$ & $\$ 9,096,493.50$ & 0.43 & 233 \\
\hline \multirow{2}{*}{$\begin{array}{l}\text { One new } \\
\text { start per } \\
\text { day }\end{array}$} & \multirow[b]{2}{*}{33.3} & \multirow[b]{2}{*}{365} & \multirow[b]{2}{*}{5475} & $\$$ & (69.35) & $\$ \quad(1,040.25)$ & -- & -- \\
\hline & & & & $\$$ & $202,144.30$ & $\$ 3,032,164.50$ & 1.30 & 77 \\
\hline \multirow{2}{*}{$\begin{array}{l}\text { Two starts } \\
\text { per day }\end{array}$} & \multirow[b]{2}{*}{66.7} & \multirow[b]{2}{*}{730} & \multirow[b]{2}{*}{10950} & $\$$ & (138.70) & $\$ \quad(2,080.50)$ & -- & -- \\
\hline & & & & $\$$ & $404,288.60$ & $\$ 6,064,329.00$ & 0.65 & 154 \\
\hline \multirow{2}{*}{$\begin{array}{l}\text { Max per } \\
\text { one } 8 \text { hour } \\
\text { shift }\end{array}$} & \multirow[b]{2}{*}{33.3} & \multirow[b]{2}{*}{365} & \multirow[b]{2}{*}{5475} & $\$$ & $(69.35)$ & $\$ \quad(1,040.25)$ & -- & -- \\
\hline & & & & $\$$ & $202,144.30$ & $\$ 3,032,164.50$ & 1.30 & 77 \\
\hline \multirow{2}{*}{$\begin{array}{l}\text { One new } \\
\text { print } \\
\text { weekly }\end{array}$} & \multirow[b]{2}{*}{4.8} & \multirow[b]{2}{*}{52} & \multirow[b]{2}{*}{780} & $\$$ & $(9.88)$ & $(148.20)$ & -- & -- \\
\hline & & & & $\$$ & $28,798.64$ & $\$ 431,979.60$ & 9.12 & 7 \\
\hline
\end{tabular}

\section{Discussion}

Like most manufacturing equipment purchases, the potential cost benefit of the Gigabot X system is dependent on the relative value of the manufactured components, the cost of materials and the maximum capacity factor at which the system can be successfully operated. However, among AM systems there exist potential incentives due to the Gigabot X systems unique ability to use recycled waste plastics without the need to first turn these plastics into commercial grade filament.

Tables 4 through 6 summarize the potential cost benefits of manufacturing and selling case study products at current market prices using the greenest option of locally-sourced recycled waste plastic and on site shredding. The labor costs were not included as those would be highly variable throughout the locations of fab labs all over the world. For example the high-end of costs could be for professional machinists in European markets using the Gigabot $\mathrm{X}$ as one of the tools in their specialty shops; whereas the low end could come from using 'free' secretary time for reloading polymer feedstock in the printer while otherwise answering phones or manning a front desk. It should be noted that the vast majority of the time the Gigabot X would run unattended during its long prints so the actual labor involved in printing a pre-designed object is minimal. In addition to the labor costs, the profit and markup were similarly excluded as again this would be highly variable depending on the market. However, using the foundational economic information found here, fab labs or other small and medium sized enterprises (SMEs) can quickly determine if the labor rates they use would make the use of a Gigabot $\mathrm{X}$ a useful investment for their enterprise by providing a high enough profit potential. In addition, the results here can be used for direct self-production as in distributed manufacturing-based case studies of consumers [48, 83, 95, 96]. Although the Gigabot X could be used as a 'factory in a box' for a single product as shown here, most likely it would be used to print a wide variety of products 
Preprint: Dennis J. Byard, Aubrey L. Woern, Robert B. Oakley, Matthew J. Fiedler, Samantha L. Snabes, and Joshua M. Pearce. Green Fab Lab Applications of Large-Area Waste Polymer-based Additive Manufacturing. Additive Manufacturing (2019, in press).

https://doi.org/10.1016/j.addma.2019.03.006

even in a given fab lab. It would also be used for prototyping new products, which in general would provide much more value per hour of printing times shown here. The Gigabot X system, coupled with usage of shredded waste plastic, lends itself to being particularly beneficial in developing economies where poor access to many commercial products is limited [97-105]. There is thus an urgent need for a low cost open source shredder. Several have been developed already [106-108] and there may be a larger version to be made available for fab labs operating several Gigabot X 3D printers simultaneously.

This study had several limitations. First, only a few types of products were investigated over a single run. Additional research would be necessary to optimize each individual product and to analyze the economics of a Gigabot X-based fab lab using many waste polymer feed stocks as well as a realistic basket of large products appropriate for the Gigabot platform. These might include furniture, tools, lower limb prosthetics, medical models or tools, manufacturing fixtures and jigs, or specialized casings or shrouds for equipment. In addition, products that have higher functionality, but our based on a Gigabot X print should be investigated. For example, the skateboard deck could be used for a 3D printable electric skateboard [109] with a higher retail value of \$750-\$1000 [110].

Further research needs to be conducted both in factoring the impact of labor costs and or employment opportunities provided by the Gigabot X. In locations with unstable electric grids, the usage of solar photovoltaic systems could potentially provide not only a stable power source, but additional cost savings when coupled with shredded waste plastic. There has been significant progress in this area of solar powered distributed manufacturing with AM systems [37, 111-115], and users have already taken the Gigabot off grid with solar photovoltaic-battery systems [116].

\section{Conclusions}

This study found that the Gigabot X, an open source industrial FPF/FGF 3D printer, has significant economic potential when used as a distributed recycling/manufacturing system using recyclable feed stocks in the green fab lab context. The results showed that FPF/FGF 3D printing is capable of producing large high-value sporting goods products with the three case studies. The system was shown to be relatively energy efficient so that the costs of electricity were not overly important for such manufactured products unless they were small. In all cases a substantial economic savings was observed when comparing the materials and energy related costs to commercial goods. This was even the case when the 3D printed products were substantially customized. Using locally-sourced shredded plastic represented not only the best environmental option, but also the most economic. For some of the case study products analyzed even the lowest capacity factor (starting only one print per week) represented a profit when comparing to the more legitimate high-end product. When comparing to the low-end in general the Gigabot X needed to be used at a higher capacity. For some products the profit potential and return on investment was substantial (e.g. over 1000\%) for high capacity use of a Gigabot $\mathrm{X}$. These results clearly show that the economic benefit of distributed recycling and on demand production of large, functional objects using an integrated FPF/FGF tool to promote circular manufacturing.

\section{Acknowledgements}

This research was supported by NSF SBIR Phase I grant number: 1746480 and the WeWork Global 
Preprint: Dennis J. Byard, Aubrey L. Woern, Robert B. Oakley, Matthew J. Fiedler, Samantha L. Snabes, and Joshua M. Pearce. Green Fab Lab Applications of Large-Area Waste Polymer-based Additive Manufacturing. Additive Manufacturing (2019, in press).

https://doi.org/10.1016/j.addma.2019.03.006

Creator Award.

8. Conflicts of Interest: RO, MF and SS are employees of re:3D, which manufacturers the Gigabot $\mathrm{X}$ used in this study. All data was collected by the author from MTU, which have no conflicts of interest. The funders played no part in the design of the study; in the collection, analyses or interpretation of data; in the writing of the manuscript, or in the decision to publish the results.

\section{References}

1. Gershenfeld, N., 2008. Fab: the coming revolution on your desktop--from personal computers to personal fabrication. Basic Books.

2. Walter-Herrmann, J. and Büching, C. eds., 2014. FabLab: Of machines, makers and inventors. transcript Verlag.

3. Mikhak, B., Lyon, C., Gorton, T., Gershenfeld, N., McEnnis, C. and Taylor, J., 2002, December. Fab Lab: an alternate model of ICT for development. In 2nd international conference on open collaborative design for sustainable innovation.

4. FabLabs. https://www.fablabs.io/ (accessed on Feb 15, 2019)

5. Stacey, M., 2014. The FAB LAB network: A global platform for digital invention, education and entrepreneurship. Innovations: Technology, Governance, Globalization, 9(1-2), pp.221-238.

6. FabLab Map. https://www.fablabs.io/labs/map (accessed on Feb 15, 2019)

7. Mandavilli, A., 2006. Appropriate technology: Make anything, anywhere. Nature volume 442, pages 862-864 (24 August 2006)

8. Pearce, J.M., 2012. The case for open source appropriate technology. Environment, Development and Sustainability, 14(3), pp.425-431.

9. Pearce, J.M., Blair, C.M., Laciak, K.J., Andrews, R., Nosrat, A. and Zelenika-Zovko, I., 2010. 3-D printing of open source appropriate technologies for self-directed sustainable development. Journal of sustainable development, 3(4), p.17.

10. Personal communication Phillip Allore July 19, 2018.

11. Kostakis, V., Niaros, V., Dafermos, G. and Bauwens, M., 2015. Design global, manufacture local: Exploring the contours of an emerging productive model. Futures, 73, pp.126-135.

12. Arvidsson, A., Caliandro, A., Cossu, A., Deka, M., Gandini, A., Luise, V. and Anselmi, G., 2016. Commons based peer production in the information economy.

13. Benyus, J.M., 1997. Biomimicry: Innovation inspired by nature. Harper.

14. Peters, T., 2011. Nature as measure: The biomimicry guild. Architectural Design, 81(6), pp.4447.

15. Goss, J., 2009. Biomimicry: Looking to nature for design solutions. Corcoran College of Art+ Design.

16. Lyle, J.T., 1996. Regenerative design for sustainable development. John Wiley \& Sons.

17. Cole, R.J., 2012. Transitioning from green to regenerative design. Building Research \& Information, 40(1), pp.39-53.

18. Svec, P., Berkebile, R. and Todd, J.A., 2012. REGEN: toward a tool for regenerative thinking. Building Research \& Information, 40(1), pp.81-94.

19. Gibb, A., 2014. Building open source hardware: DIY manufacturing for hackers and makers. Pearson Education. 
Preprint: Dennis J. Byard, Aubrey L. Woern, Robert B. Oakley, Matthew J. Fiedler, Samantha L. Snabes, and Joshua M. Pearce. Green Fab Lab Applications of Large-Area Waste Polymer-based Additive Manufacturing. Additive Manufacturing (2019, in press).

https://doi.org/10.1016/j.addma.2019.03.006

20. Ghisellini, P., Cialani, C. and Ulgiati, S., 2016. A review on circular economy: the expected transition to a balanced interplay of environmental and economic systems. Journal of Cleaner production, 114, pp.11-32.

21. Geissdoerfer, M., Savaget, P., Bocken, N.M. and Hultink, E.J., 2017. The Circular Economy-A new sustainability paradigm?. Journal of Cleaner Production, 143, pp.757-768.

22. Preston, F., 2012. A global redesign?: Shaping the circular economy. London: Chatham House.

23. GreenFabLab. http://greenfablab.org/ (accessed on Feb 15, 2019)

24. Sáez, César García. "We need to make (almost) everything." (2016). http://www.fundacionorange.es/wp-content/uploads/2016/08/Estudio Fablabs Casi Todo por hacer en.pdf

25. Cerdas, F., Juraschek, M., Thiede, S. and Herrmann, C., 2017. Life cycle assessment of 3D printed products in a distributed manufacturing system. Journal of Industrial Ecology, 21(S1), pp.S80-S93.

26. Kohtala, C., 2015. Addressing sustainability in research on distributed production: an integrated literature review. Journal of Cleaner Production, 106, pp.654-668.

27. Chen, D., Heyer, S., Ibbotson, S., Salonitis, K., Steingrímsson, J.G. and Thiede, S., 2015. Direct digital manufacturing: definition, evolution, and sustainability implications. Journal of Cleaner Production, 107, pp.615-625.

28. Kreiger, M. and Pearce, J.M., 2013. Environmental impacts of distributed manufacturing from 3-D printing of polymer components and products. MRS Online Proceedings Library Archive, 1492, pp.85-90.

29. Kreiger, M. and Pearce, J.M., 2013. Environmental life cycle analysis of distributed threedimensional printing and conventional manufacturing of polymer products. ACS Sustainable Chemistry \& Engineering, 1(12), pp.1511-1519.

30. Sanchez, F.A.C., 2016. Methodological proposition to evaluate polymer recycling in opensource additive manufacturing contexts (Doctoral dissertation, Université de Lorraine).

31. Baechler, C., DeVuono, M. and Pearce, J.M., 2013. Distributed recycling of waste polymer into RepRap feedstock. Rapid Prototyping Journal, 19(2), pp.118-125.

32. Kreiger, M., Anzalone, G.C., Mulder, M.L., Glover, A. and Pearce, J.M., 2013. Distributed recycling of post-consumer plastic waste in rural areas. MRS Online Proceedings Library Archive, 1492, pp.91-96.

33. Kreiger, M.A., Mulder, M.L., Glover, A.G. and Pearce, J.M., 2014. Life cycle analysis of distributed recycling of post-consumer high density polyethylene for 3-D printing filament. Journal of Cleaner Production, 70, pp.90-96.

34. Zhong, S., Rakhe, P. and Pearce, J.M., 2017. Energy payback time of a solar photovoltaic powered waste plastic recyclebot system. Recycling, 2(2), p.10. https://doi.org/10.3390/recycling2020010

35. Zhong, S. and Pearce, J.M., 2018. Tightening the loop on the circular economy: Coupled distributed recycling and manufacturing with recyclebot and RepRap 3-D printing. Resources, Conservation and Recycling, 128, pp.48-58.

36. Recyclebot. Appropedia. http://www.appropedia.org/Recyclebot (accessed 12.19.2017).

37. Sells, E., Bailard, S., Smith, Z., Bowyer, A. and Olliver, V., 2010. RepRap: the replicating rapid prototyper: maximizing customizability by breeding the means of production. In Handbook of Research in Mass Customization and Personalization: (In 2 Volumes) (pp. 568-580).

38. Jones, R., Haufe, P., Sells, E., Iravani, P., Olliver, V., Palmer, C. and Bowyer, A., 2011. 
Preprint: Dennis J. Byard, Aubrey L. Woern, Robert B. Oakley, Matthew J. Fiedler, Samantha L. Snabes, and Joshua M. Pearce. Green Fab Lab Applications of Large-Area Waste Polymer-based Additive Manufacturing. Additive Manufacturing (2019, in press).

https://doi.org/10.1016/j.addma.2019.03.006

RepRap-the replicating rapid prototyper. Robotica, 29(1), pp.177-191.

39. Bowyer, A. 3D Printing and Humanity's First Imperfect Replicator. 3D Printing and Additive Manufacturing 2014, 1 (1): 4-5.

40. Woern, A.L., McCaslin, J.R., Pringle, A.M. and Pearce, J.M., 2018. RepRapable Recyclebot: Open source 3-D printable extruder for converting plastic to 3-D printing filament. HardwareX, 4, p.e00026.

41. Cruz Sanchez, F., Lanza, S., Boudaoud, H., Hoppe, S., \& Camargo, M. Polymer Recycling and Additive Manufacturing in an Open Source context: Optimization of processes and methods. In 2015 Annual International Solid Freeform Fabrication Symposium-An Additive Manufacturing Conference, Austin, Texas (USA) 2015 (pp. 10-12).

42. Cruz Sanchez, F. A. C., Boudaoud, H., Hoppe, S., \& Camargo, M. Polymer recycling in an open-source additive manufacturing context: Mechanical issues. Additive Manufacturing 2017, 17, 87-105.

43. Anderson, I. Mechanical Properties of Specimens 3D Printed with Virgin and Recycled Polylactic Acid. 3D Printing and Additive Manufacturing 2017, 4, 110-115, doi:10.1089/3dp.2016.0054.

44. Pakkanen, J., Manfredi, D., Minetola, P., Iuliano, L. About the Use of Recycled or Biodegradable Filaments for Sustainability of 3D Printing. In Sustainable Design and Manufacturing 2017; Smart Innovation, Systems and Technologies; Springer, Cham, 2017; pp. 776-785.

45. Mohammed, M. I., Mohan, M., Das, A., Johnson, M. D., Badwal, P. S., McLean, D., Gibson, I. A low carbon footprint approach to the reconstitution of plastics into 3D-printer filament for enhanced waste reduction. KnE Engineering, 2017, 2, 234-241.

46. Chong, S., Pan, G.-T., Khalid, M., Yang, T. C.-K., Hung, S.-T., Huang, C.-M. Physical Characterization and Pre-assessment of Recycled High-Density Polyethylene as 3D Printing Material. Journal of Polymers and the Environment, 2017, 25(2), 136-145. doi:10.1007/s10924016-0793-4.

47. Mohammed, M. I., Das, A., Gomez-Kervin, E., Wilson, D., Gibson, I. EcoPrinting: Investigating the use of 100\% recycled Acrylonitrile Butadiene Styrene (ABS) for Additive Manufacturing. Solid Freeform Fabrication 2017. Proceedings of the 28th Annual International Solid Freeform Fabrication Symposium. 2017.

http://sffsymposium.engr.utexas.edu/sites/default/files/2017/Manuscripts/ EcoprintingInvestigatingtheUseof100Recycle.pdf

48. Woern, A.L. and Pearce, J.M., 2017. Distributed manufacturing of flexible products: Technical feasibility and economic viability. Technologies, 5(4), 71; https://doi.org/10.3390/technologies5040071

49. Pringle, A. M.; Rudnicki, M.; Pearce, J. Wood Furniture Waste-Based Recycled 3-D Printing Filament. Forest Products Journal. (in press) https://doi.org/10.13073/FPJ-D-17-00042

50. Tian, X.; Liu, T.; Wang, Q.; Dilmurat, A.; Li, D.; Ziegmann, G. Recycling and remanufacturing of 3D printed continuous carbon fiber reinforced PLA composites. Journal of Cleaner Production 2017, 142, 1609-1618, doi:10.1016/j.jclepro.2016.11.139.

51. Oblak, P., Gonzalez-Gutierrez, J., Zupančič, B., Aulova, A. and Emri, I., 2015. Processability and mechanical properties of extensively recycled high density polyethylene. Polymer Degradation and Stability, 114, pp.133-145.

52. Lee, J.H., Lim, K.S., Hahm, W.G. and Kim, S.H., 2013. Properties of recycled and virgin poly 
Preprint: Dennis J. Byard, Aubrey L. Woern, Robert B. Oakley, Matthew J. Fiedler, Samantha L. Snabes, and Joshua M. Pearce. Green Fab Lab Applications of Large-Area Waste Polymer-based Additive Manufacturing. Additive Manufacturing (2019, in press).

https://doi.org/10.1016/j.addma.2019.03.006

(ethylene terephthalate) blend fibers. Journal of Applied Polymer Science, 128(2), pp.12501256.

53. Beaudoin, A., JMS-1704: Multihead 3D Printer (Doctoral dissertation, Worcester Polytechnic Institute) 2016.

54. Volpato, N., Kretschek, D., Foggiatto, J.A. and da Silva Cruz, C.G., Experimental analysis of an extrusion system for additive manufacturing based on polymer pellets. The International Journal of Advanced Manufacturing Technology, 2015. 81(9-12), pp.1519-1531.

55. Whyman, S.; Arif, K. M.; Potgieter, J. Design and development of an extrusion system for 3D printing biopolymer pellets. The International Journal of Advanced Manufacturing Technology, 2018, 96, 3417-3428, doi:10.1007/s00170-018-1843-y.

56. Liu, X., Chi, B., Jiao, Z., Tan, J., Liu, F. and Yang, W., 2017. A large-scale double-stage-screw 3 D printer for fused deposition of plastic pellets. Journal of Applied Polymer Science, 134(31), p.45147.

57. Giberti, H., Sbaglia, L. and Silvestri, M., 2017. Mechatronic Design for an Extrusion-Based Additive Manufacturing Machine. Machines, 5(4), p.29 , doi:10.3390/machines5040029.

58. Giberti, H. and Sbaglia, L., 2017, June. A Robotic Design for a MIM Based Technology. In International Conference on Robotics in Alpe-Adria Danube Region (pp. 565-572). Springer, Cham.

59. Braanker, G.B., Duwel, J.E.P., Flohil, J.J. and Tokaya, G.E., Developing a plastics recycling add-on for the RepRap 3D-printer. Delft University of Technology, 2010.

60. Horne, R. Reprap development and further adventures in DIY 3D printing: No more filament? Quest for a Universal Pellet Extruder for 3D Printing. Reprap development and further adventures in DIY 3D printing 2014. https://richrap.blogspot.com/2014/12/no-more-filamentquest-for-universal.html

61. Universal Pellet Extruder. http://upe3d.blogspot.com/

62. Wang, Z., Liu, R., Sparks, T. and Liou, F., 2016. Large-Scale Deposition System by an Industrial Robot (I): Design of Fused Pellet Modeling System and Extrusion Process Analysis. 3D Printing and Additive Manufacturing, 3(1), pp.39-47.

63. The PartDaddy - Large Format Delta 3D Printer - Custom Available online: https://www.seemecnc.com/products/partdaddy-large-format-delta-3d-printer (accessed on Jul 9, 2018).

64. Cheetah Pro Large Format 3D Printer by Hans Fouche Available online: http://www.fouche3dprinting.com (accessed on Jul 9, 2018).

65. Introducing David Available online: /pages/david (accessed on Jul 9, 2018).

66. Erecto-Struder 24v, ErectorBot Store Available online: http://www.erectorbot.com/store/product_info.php?cPath=23\&products_id=65 (accessed on Jul 9, 2018).

67. Gigabot X: Large-Scale, Recycled Plastic Pellet 3D Printer Available online: https://www.kickstarter.com/projects/re3d/gigabot-X-your-direct-pellet-extrusion-3d-printer (accessed on Jul 9, 2018).

68. Kohtala, C., 2013. Shaping sustainability in fab labs. In Participatory Innovation Conference (pp. 287-290). Lahti: Lappeenranta University of Technology.

69. Kohtala, C., 2016. Making sustainability: how Fab Labs address environmental issues. Aalto University.

70. Kohtala, C., 2017. Making “Making” Critical: How Sustainability is Constituted in Fab Lab 
Preprint: Dennis J. Byard, Aubrey L. Woern, Robert B. Oakley, Matthew J. Fiedler, Samantha L. Snabes, and Joshua M. Pearce. Green Fab Lab Applications of Large-Area Waste Polymer-based Additive Manufacturing. Additive Manufacturing (2019, in press).

https://doi.org/10.1016/j.addma.2019.03.006

Ideology. The Design Journal, 20(3), pp.375-394.

71. Woern A.L., Byard D.J., OakleyR.B., Fiedler M.J., Snabes S.L., Pearce, J.M. Fused Particle Fabrication 3-D Printing: Recycled Materials Optimization and Mechanical Properties, Materials 2018, 11, 1413. doi: 10.3390/ma11081413

72. Slic3r - G-code generator for 3D printers - Available online: http://slic3r.org (accessed on Jul 10, 2018).

73. Marlin Firmware - Available online: http://marlinfw.org (accessed on Jul 10, 2018).

74. Heikkinen, I.T., Kauppinen, C., Liu, Z., Asikainen, S.M., Spoljaric, S., Seppälä, J.V., Savin, H. and Pearce, J.M., 2018. Chemical Compatibility of Fused Filament Fabrication-based 3-D Printed Components with Solutions Commonly Used in Semiconductor Wet Processing. Additive Manufacturing. (in press) https://doi.org/10.1016/j.addma.2018.07.015

75. U.S. Energy Information Administration - Electric Power Monthly - Available Online: https://www.eia.gov/electricity/monthly/epm table grapher.php?t=epmt 56 a (accessed on Aug 03, 2018)

76. Amazon - Available Online: https://www.amazon.com/3D-Solutech-Yellow-PrinterFilament/dp/B00MWLDGWY/ref=sr_1_2_sspa?

s=industrial\&ie=UTF8\&qid $=1533306824 \& s r=1-2-$ spons\&keywords=abs+filament\&psc $=1$ (accessed on Aug 03, 2018)

77. Amazon - Available Online: https://www.amazon.com/IC3D-Black-1-75mm-PrinterFilament/dp/B075787JC7/ref=sr_1_19? s=industrial\&ie=UTF8\&qid=1533306824\&sr=1-19\&keywords=abs+filament (accessed on Aug 03, 2018)

78. Premier Plastic Resins - ABS - Available Online: http://www.premierplasticresins.com/abs.html (accessed on Aug 03, 2018)

79. Alibaba - Recycled ABS Plastic Scrap Prices Granule Pellets - Available Online: https:// www.alibaba.com/product-detail/Recycled-ABS-Plastic-Scrap-PricesGranule_60767093086.html?spm=a2700.7724857.normalList.25.2f3d597aBceLnx (accessed on Aug 03, 2018)

80. Mcdunnough - Inventory - Available Online: http://www.mcdunnough.com/recycledplastic-materials.php (accessed on Aug 03, 2018)

81. Blender. https://www.blender.org/ (accessed on Feb 15, 2019)

82. FreeCAD. https://www.freecadweb.org/ (accessed on Feb 15, 2019)

83. Wittbrodt, B.T., Glover, A.G., Laureto, J., Anzalone, G.C., Oppliger, D., Irwin, J.L. and Pearce, J.M., 2013. Life-cycle economic analysis of distributed manufacturing with open-source 3-D printers. Mechatronics, 23(6), pp.713-726.

84. Pearce, J.M., Denkenberger, D. and Zielonka, H., 2009. Accelerating applied sustainability by utilizing return on investment for energy conservation measures. International Journal of Energy, Environment and Economics, 17(1), 61-80.

85. Kreiger, M., Anzalone, G.C., Mulder, M.L., Glover, A. and Pearce, J.M., 2013. Distributed recycling of post-consumer plastic waste in rural areas. MRS Online Proceedings Library Archive, 1492, pp.91-96.

86. Kreiger, M.A., Mulder, M.L., Glover, A.G. and Pearce, J.M., 2014. Life cycle analysis of distributed recycling of post-consumer high density polyethylene for 3-D printing filament. 
Preprint: Dennis J. Byard, Aubrey L. Woern, Robert B. Oakley, Matthew J. Fiedler, Samantha L. Snabes, and Joshua M. Pearce. Green Fab Lab Applications of Large-Area Waste Polymer-based Additive Manufacturing. Additive Manufacturing (2019, in press).

https://doi.org/10.1016/j.addma.2019.03.006

Journal of Cleaner Production, 70, pp.90-96.

87. Kreiger, M. and Pearce, J.M., 2013. Environmental impacts of distributed manufacturing from 3-D printing of polymer components and products. MRS Online Proceedings Library Archive, 1492, pp.85-90.

88. Kreiger, M. and Pearce, J.M., 2013. Environmental life cycle analysis of distributed threedimensional printing and conventional manufacturing of polymer products. ACS Sustainable Chemistry \& Engineering, 1(12), pp.1511-1519.

89. Amazon - Available online - https://www.amazon.com/MPI-Mahogany-Skateboard-Light-23125/dp/B01FN90CPA/ref=sr_1_1?s=outdoor-recreation\&ie=UTF8\&qid=1533504785\&sr=1$1 \&$ keywords=skateboard+deck (accessed on Aug 05, 2018)

90. Amazon - Available online - https://www.amazon.com/Santa-Cruz-Collectible-SkateboardAssorted/dp/B00PM3KRZI/ref=sr 1 1?s=outdoorrecreation\&ie=UTF8\&qid=1533504900\&sr=1-1\&keywords=skateboard + deck (accessed on Aug 05, 2018)

91. Amazon - Available online - https://www.amazon.com/Werner-Ovation-Carbon-Shaft-Paddle$220 \mathrm{~cm} / \mathrm{dp} / \mathrm{B} 00 \mathrm{H} 90 \mathrm{KBJY} / \mathrm{ref}=$ sr_1_9?s=outdoorrecreation\&ie=UTF8\&qid=1517718906\&sr=1-9\&refinements=p_36\%3A1253559011 (accessed on Aug 07, 2018)

92. Amazon - Available online - https://www.amazon.com/Goplus-Snowshoes-Anti-ShockAdjustable-Carrying/dp/B01N97PI6A/ref=sr_1_8?ie=UTF8\&qid=1518181648\&sr=88\&keywords=snow+shoes (accessed on April 23 , 2018)

93. Amazon - Available online - https://www.amazon.com/SEAFLO-Child-0-9lbs-Shaft-Paddle/dp/ B07586V3DQ/ref=sr_1_8?s=outdoor-recreation\&ie=UTF8\&qid=1517718809\&sr=18\&refinements=p_36\%3A1253555011 (accessed on April 23, 2018)

94. Amazon - Available online - https://www.amazon.com/Werner-Ovation-Carbon-Shaft-Paddle$220 \mathrm{~cm} / \mathrm{dp} / \mathrm{B} 00 \mathrm{H} 90 \mathrm{KBJY} / \mathrm{ref}=\mathrm{sr} \_1 \_9$ ?s=outdoorrecreation\&ie=UTF8\&qid=1517718906\&sr=1-9\&refinements=p_36\%3A1253559011 (accessed on April 23, 2018).

95. Petersen, E. and Pearce, J., 2017. Emergence of home manufacturing in the developed world: Return on investment for open-source 3-D printers. Technologies, 5(1), 7; doi:10.3390/technologies5010007.

96. Petersen, E., Kidd, R. and Pearce, J., 2017. Impact of DIY home manufacturing with 3D printing on the toy and game market. Technologies, 5(3), 45; doi: 10.3390/technologies5030045.

97. Feeley, S.R., Wijnen, B. and Pearce, J.M., 2014. Evaluation of potential fair trade standards for an ethical 3-D printing filament. Journal of Sustainable Development, 7(5), 1-12. DOI: 10.5539/ jsd.v7n5p1

98. Birtchnell, T. and Hoyle, W., 2014. The 3D4D Elements. In 3D Printing for Development in the Global South: The 3D4D Challenge (pp. 81-95). Palgrave Pivot, London.

99. Birtchnell, T. and Hoyle, W., 2014. 3D4D Indicators and Forerunners. In 3D Printing for Development in the Global South: The 3D4D Challenge (pp. 96-112). Palgrave Pivot, London.

100. Ishengoma, F.R. and Mtaho, A.B., 2014. 3D printing: developing countries perspectives. arXiv preprint arXiv:1410.5349.

101. Sun, L. and Zhao, L., 2017. Envisioning the era of 3D printing: a conceptual model for the fashion industry. Fashion and Textiles, 4(1), p.25.

102. Pelley, J., 2014. Fair-trade plastic for 3D printers. 
Preprint: Dennis J. Byard, Aubrey L. Woern, Robert B. Oakley, Matthew J. Fiedler, Samantha L. Snabes, and Joshua M. Pearce. Green Fab Lab Applications of Large-Area Waste Polymer-based Additive Manufacturing. Additive Manufacturing (2019, in press).

https://doi.org/10.1016/j.addma.2019.03.006

103. Birtchnell, T. and Hoyle, W., 2014. The 3D4D Challenge. In 3D Printing for

Development in the Global South: The 3D4D Challenge (pp. 13-35). Palgrave Pivot, London.

104. Birtchnell, T. and Hoyle, W., 2014. 3D printing for development in the global south: The 3D4D challenge. Springer.

105. Sniderman, B., Baum, P. and Rajan, V., Additive manufacturing and humanitarian aid. Managing Humanitarian Innovation, p.117.

106. \$50 PLASTIC SHREDDER / GRINDER / RECYCLER available :

https://www.instructables.com/id/50-Plastic-Shredder-Grinder-Recycler/ (accessed 8.13.2018).

107. Mini shredder with housing http://filamaker.eu/product/harddrive-destroyer/ (accessed 8.13.2018).

108. Shredder machine. https://preciousplastic.com/en/videos/build/shredder.html (accessed 8.13.2018).

109. Woern. A. 3D Printed Electric Skateboard https://www.myminifactory.com/object/3dprint-81246 (accessed 2-19-2019).

110. Boosted. Boosted Mini. https://boostedboards.com/boards/boosted-mini (accessed 2-192019).

111. King, D.L., Babasola, A., Rozario, J. and Pearce, J.M., 2014. Mobile open-source solarpowered 3-D printers for distributed manufacturing in off-grid communities. Challenges in Sustainability 2(1), 18-27.

112. Wong, J.Y., 2015. Ultra-portable solar-powered 3D printers for onsite manufacturing of medical resources. Aerospace medicine and human performance, 86(9), pp.830-834.

113. Gwamuri, J., Franco, D., Khan, K.Y., Gauchia, L. and Pearce, J.M., 2016. Highefficiency solar-powered 3-D printers for sustainable development. Machines 4(1), 3; doi: 10.3390/machines4010003

114. Khan, K.Y., Gauchia, L. and Pearce, J.M., 2018. Self-sufficiency of 3-D printers: utilizing stand-alone solar photovoltaic power systems. Renewables: Wind, Water, and Solar, 5(1), p.5. doi: 10.1186/s40807-018-0051-6

115. Zhong, S., Rakhe, P. and Pearce, J.M., 2017. Energy payback time of a solar photovoltaic powered waste plastic recyclebot system. Recycling 2017, 2(2), 10; doi: 10.3390/recycling2020010

116. Gerty, C. How to take your Gigabot Off-the-Grid Jan 14, 2015) re3d.org. https://re3d.org/3d-printing-off-the-grid/ (accessed 8.13.2018). 